\title{
Autophagy in Peripheral Neuropathy
}

\author{
Ayman Osman
}

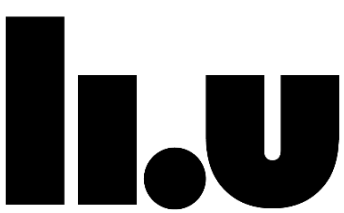

LINKÖPING UNIVERSITY

Department of Clinical and Experimental Medicine Linköping University, Sweden Linköping 2017 
Autophagy in Peripheral Neuropathy

(C)Ayman Osman, 2017

Cover/picture/Illustration/Design:

The cover picture by Kristin Samuelsson from Karolinska institute. All electron microscope pictures by Simin Mohseni and Ayman Osman. Confocal microscope pictures by Ayman Osman. Illustrations by Ayman Osman.

Published article has been reprinted with the permission of the copyright holder.

Printed in Sweden by LiU-Tryck, Linköping, Sweden, 2017

ISBN: 978-91-7685-472-3

ISSN: 0345-0082 
To my mother 


\section{Supervisor:}

Simin Mohseni, Associate Professor.

Department of Clinical and Experimental Medicine (IKE), Linköping University Linköping, Sweden.

\section{Co-supervisor:}

Lars Dahlin, Professor and Senior Consultant in Hand Surgery.

Department of Translational Medicine - Hand Surgery, Faculty of Medicine, Lund University.

David Engblom, Associate Professor.

Department of Clinical and Experimental Medicine (IKE), Linköping University Linköping, Sweden.

Maria Turkina, Associate Professor.

Department of Clinical and Experimental Medicine (IKE), Linköping University, Linköping, Sweden.

\section{Faculty opponent:}

Kaj Fried, Professor.

Department of Neuroscience (Neuro), Karolinska Institute, Stockholm, Sweden.

\section{Committee board:}

Ebo de Muinck, Professor.

Department of Medical and Health Sciences (IMH), Linköping University, Linköping, Sweden.

Katarina Kågedal, Associate Professor.

Department of Clinical and Experimental Medicine (IKE), Linköping University, Linköping, Sweden.

Christian Bjerggaard Vægter, Associate Professor.

Department of Biomedicine, Aarhus University, Aarhus, Denmark. 


\section{ABSTRACT}

Peripheral neuropathy includes a wide range of diseases affecting millions around the world, and many of these diseases have unknown etiology. Peripheral neuropathy in diabetes represents a large proportion of peripheral neuropathies. Nerve damage can also be caused by trauma. Peripheral neuropathies are a significant clinical problem and efficient treatments are largely lacking. In the case of a transected nerve, different methods have been used to repair or reconstruct the nerve, including the use of nerve conduits, but functional recovery is usually poor.

Autophagy, a cellular mechanism that recycles damaged proteins, is impaired in the brain in many neurodegenerative diseases affecting animals and humans. No research, however, has investigated the presence of autophagy in the human peripheral nervous system. In this study, I present the first structural evidence of autophagy in human peripheral nerves. I also show that the density of autophagy structures is higher in peripheral nerves of patients with chronic idiopathic axonal polyneuropathy (CIAP) and inflammatory neuropathy than in controls. The density of these structures increases with the severity of the neuropathy.

In animal model, using Goto-Kakizaki (GK) rats with diabetes resembling human type 2 diabetes, activation of autophagy by local administration of rapamycin incorporated in collagen conduits that were used for reconnection of the transected sciatic nerve led to an increase in autophagy proteins LC3 and a decrease in p62 suggesting that the autophagic flux was activated. In addition, immunoreactivity of neurofilaments, which are parts of the cytoskeleton of axons, was increased indicating increased axonal regeneration. I also show that many proteins involved in axonal regeneration and cell survival were up-regulated by rapamycin in the injured sciatic nerve of GK rats four weeks after injury.

Taken together, these findings provide new knowledge about the involvement of autophagy in neuropathy and after peripheral nerve injury and reconstruction using collagen conduits. 


\section{Populärvetenskaplig sammanfattning}

Nervskador (neuropati) orsakade av sjukdomar eller olycksfall påverkar miljontals individer runt om i världen. Nervskador som orsakas av diabetes kallas diabetesneuropati och drabbar varannan patient med diabetes. Neuropati kan också orsakas av kronisk inflammation i nerven eller uppstå utan känd orsak, så kallad kronisk idiopatisk axonal polyneuropati. Patienterna som drabbas av neuropati uppvisar varierande symptom beroende på vilka nerver som drabbas men domningar, stickningar, smärta, känselbortfall och muskelsvaghet finns ofta i symptombilden. Nervskador efter trauma kräver oftast kirurgisk rekonstruktion.

För närvarande finns det ingen behandling för diabetesneuropati. Allt fler människor i fysiskt aktiv ålder drabbas av åldersdiabetes (typ 2 diabetes). Detta leder till att fler patienter med diabetes drabbas av traumatiska nervskador som kräver nervreparation. Det är därför viktigt att utveckla reparationsmetoder som fungerar bra för dessa patienter. Idag används olika metoder för att reparera en avklippt nerv men den funktionella återhämtningen av nerven är tyvärr dålig.

Autofagi betyder självätande (att äta sig själv) och är en återvinningsmekanism som celler använder för att återvinna nödvändiga beståndsdelar från sina skadade delar. Denna avfallshantering är en viktig funktion för att cellen ska må bra och överleva t.ex. vid näringsbrist eller infektioner. När autofagi inte fungerar optimalt kan skadliga beståndsdelar samlas i cellen och orsaka celldöd. Bristande autofagi kan bland annat bidra till neurodegenerativa sjukdomar som Alzheimers sjukdom.

Det har varit okänt huruvida autofagi förekommer i människans perifera nerver, d.v.s. nerver utanför hjärnan och ryggmärgen. I denna avhandling presenterar jag de första strukturella bevisen på att autofagi förekommer i perifera nerver hos människor. Vi visar också att det finns ett högre antal autofagi-strukturer i nerver hos patienter med diabetesneuropati, inflammatorisk neuropati, eller kronisk idiopatisk axonal polyneuropati (CIAP) än hos kontroller. Vi har vidare studerat betydelsen av autofagi i nervreparationen hos råttor som har diabetes liknande åldersdiabetes. Jag klippte av och sydde ihop ischiasnerven med hjälp av en överbryggande ledare gjord av kollagen. I en försöksgrupp innehöll ledningen även den autofagistimulerande substansen rapamycin. Våra resultat tyder på att närvaro av rapamycin påverkar tillväxten av nervfibrer och i vissa avseenden normaliserar den biokemiska miljön. Sammantaget ger dessa resultat ny kunskap om autofagins roll i perifer nervskada och reparation. 


\section{CONTENTS}

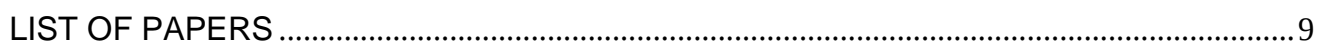

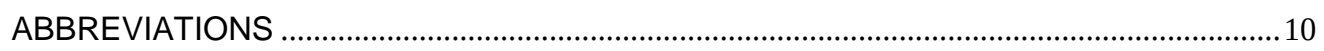

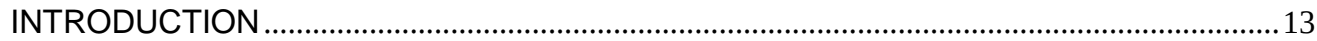

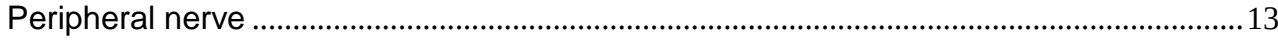

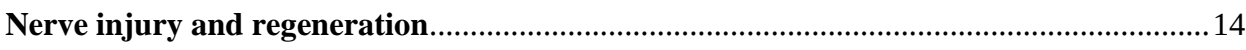

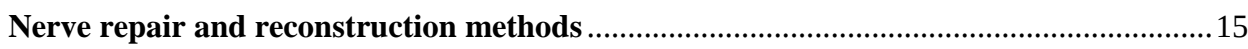

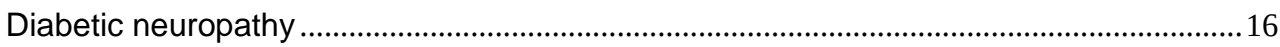

Chronic idiopathic axonal polyneuropathy ......................................................................... 18

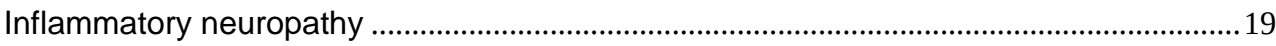

Chronic inflammatory demyelinating polyneuropathy ...............................................19

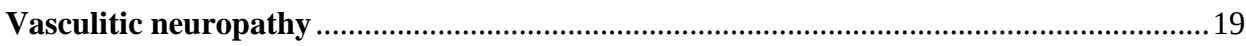

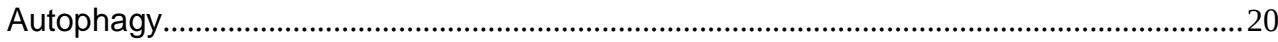

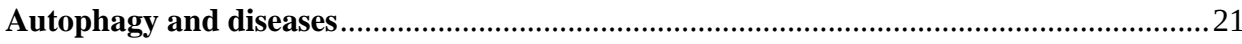

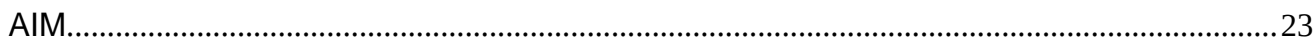

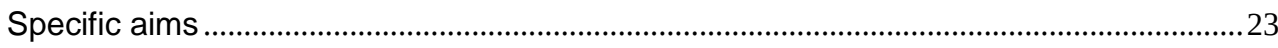

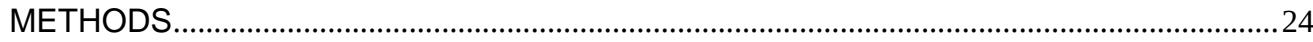

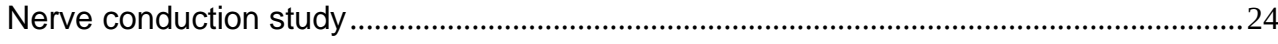

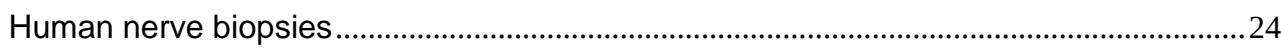

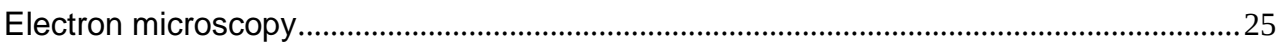

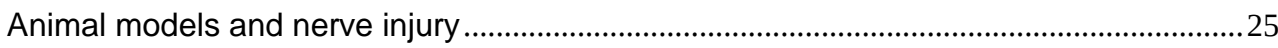

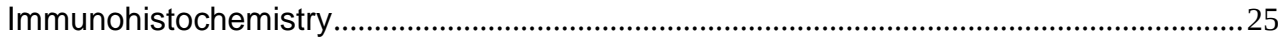

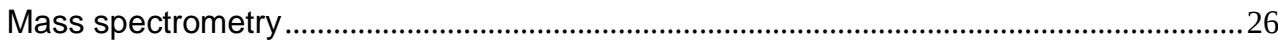

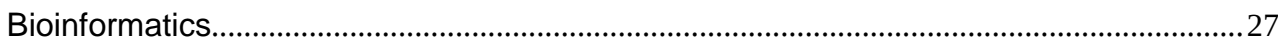

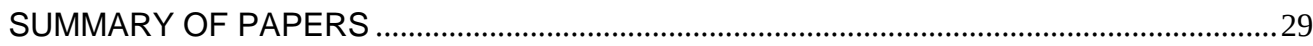

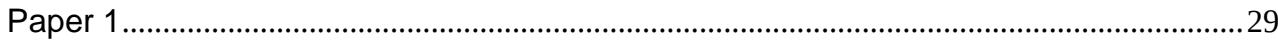

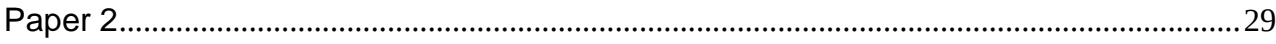

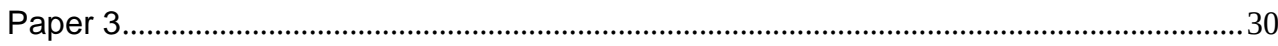

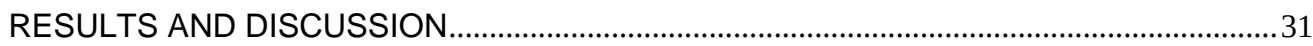

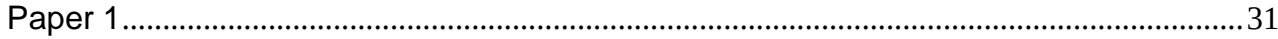

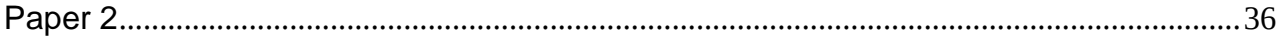

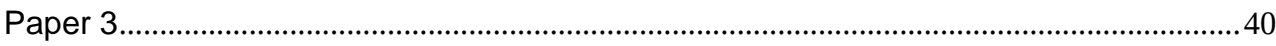

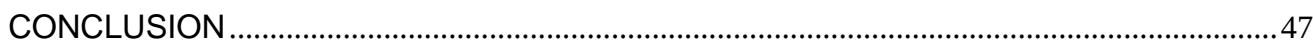

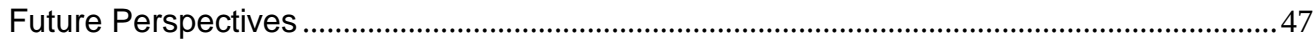

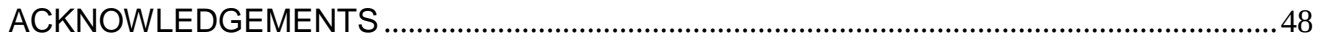


Contents

REFERENCES 


\section{LIST OF PAPERS}

I. Osman, A., Dahlin, L. B., Thomsen, N. O., \& Mohseni, S. (2015). Autophagy in the posterior interosseous nerve of patients with type 1 and type 2 diabetes mellitus: an ultrastructural study. Diabetologia, 58(3), 625-632.

II. Samuelsson, K., Osman, A., Angeria, M., Risling, M., Mohseni, S., \& Press, R. (2016). Study of autophagy and microangiopathy in sural nerves of patients with chronic idiopathic axonal polyneuropathy. PLOS ONE, 11(9), e0163427.

III. Osman, A., Arnemo, E., Turkina, M. V., Dahlin, L. B., Ratnayake, A., Rafat, M., \& Mohseni, S. Axonal regeneration and proteomic profiling of injured sciatic nerve reconstructed by NGF/rapamycin containing collagen nerve conduits in diabetic Goto-Kakizaki (GK) rats. Manuscript. 


\section{ABBREVIATIONS}

AGEs Advanced glycation end products

APOD Apolipoprotein D

APOE Apolipoprotein E

AR Aldose reductase

ATGs Autophagy proteins

BDNF Brain-derived neurotrophic factor

BNB Blood nerve barrier

CIAP Chronic idiopathic axonal polyneuropathy

CIDP Chronic inflammatory demyelination polyneuropathy

CLEAR Coordinated lysosomal expression and regulation

CMA Chaperon mediated autophagy

CMAP Compound muscle action potential

CNC Collagen nerve conduit

CNS Central nervous system

CRYAB Alpha-crystallin B chain

CSF Cerebrospinal fluid

CTS Carpal tunnel syndrome

DAN Diabetic autonomic neuropathy

DLRPN Diabetic lumbosacral radiculoplexus neuropathy

DMSO Dimethyl sulfoxide

DN Diabetic neuropathy

DPN Diabetic sensorimotor polyneuropathy

DPYSL2 Dihydropyrimidinase-related protein 2

DRG Dorsal root ganglia

EM Electron microscopy

EMG Electromyography

GAP-43 Growth associated protein 43

GBS Guillain-Barré syndrome

GDI1 Rab GDP dissociation inhibitor alpha

GDNF Glial-derived neurotrophic factor

GK Goto-Kakizaki

HTT Huntingtin

IHC Immunohistochemistry

LC3 Microtubule-associated protein 1A/1B-light chain 3 
LC-MS/MS Liquid chromatography tandem mass spectrometry

MAG Myelin-associated glycoprotein

MBP Myelin basic protein

MPZ Myelin protein zero

mTOR Mammalian target of rapamycin

NCS Nerve conduction study

NF Neurofilament

NGF Nerve growth factor

NSVN Nonsystemic vasculitic neuropathy

NT3 Neurotrophin-3

PAS Pre-autophagosomal structure

PE Phosphatidylethanolamine

PKC protein kinase $\mathrm{C}$

PLP1 Myelin proteolipid protein 1

PNS Peripheral nervous system

ROS Reactive oxygen species

SC Schwann cell

SDH Sorbitol dehydrogenase

SNAP Sensory nerve action potential

SNCA Alpha-synuclein

TEM Transmission electron microscopy

TFEB Transcription factor EB

TNF $\alpha \quad$ Tumor necrosis factor $\alpha$

TUBB3 Tubulin beta- 3 chain

TXN Thioredoxin

VEGF Vascular endothelial growth factor 


\section{INTRODUCTION}

\section{Peripheral nerve}

The peripheral nervous system (PNS) connects the central nervous system (CNS; brain and spinal cord) to body organs, and consists of motor, sensory, and autonomic nerves. A peripheral nerve is composed of many axons that are surrounded by Schwann cells (SCs). The nerve fibers together with other cells such as fibroblast, macrophages, mast cells, as well as blood vessels are embedded in connective tissue called endoneurium. A nerve fascicle is endoneurium engulfed by a connective tissue sheath called perineurium. Each nerve contains one or more fascicles (Figure 1), and these fascicles are surrounded by an outer layer of connective tissue called epineurium $[1,2]$. Some nerves include only sensory nerve fibers, called afferent nerves, which transfer nerve signals from peripheral organs to the CNS. These nerves transfer, for example, sense of pain, touch, or vibration. Other nerves include motor nerve fibers, which are efferent nerves, carrying signals from the CNS to the skeletal muscles $[1,3]$. Autonomic nerve fibers connect the CNS with internal organs and regulate the functions of cardiovascular, respiratory, digestive, and endocrine systems. Peripheral nerves may include one, two, or the three types of nerve fibers [3].

Axons in the peripheral nerves are the long process of neurons that carry nerve signals between the CNS and the innervated targets in both directions. The cell body of sensory neurons in PNS is located in the dorsal root ganglion (DRG), while the motor neuron's cell body is located in the ventral horn of the spinal cord [4]. The autonomic system is composed of sympathetic and parasympathetic systems, and the nerves have two neurons, preganglionic neurons which has the cell body in the CNS and synapse with the postganglionic axons of neurons of the autonomic ganglia in the PNS. The autonomic ganglia of the sympathetic system are located along the spinal cord, while ganglia of the parasympathetic system are located within or close to the innervated organs $[1,5]$.

SCs are a type of glial cells in the PNS. They support axons, maintain homeostasis, produce neurotrophic factors, provide myelin sheath to isolate the axons, and have an immune role during nerve injury $[4,6]$.

SC membrane is normally wrapped around the axon and isolates the axons, which leads to faster propagation of the nerve signal (action potential). In nerve fibers with a diameter of $>2 \mu \mathrm{m}$, SCs produce myelin that provides an effective isolation of the axon. Myelin is a modified SC membrane consisting of lipids and proteins. Small myelinated fibers have a diameter that varies between 2 to $6 \mu \mathrm{m}$, while large myelinated fibers have a diameter between 8 to $12 \mu \mathrm{m}$. Axons with a diameter smaller than $1 \mu \mathrm{m}$ remain unmyelinated $[1,2,7$, $8]$.

Most of the nerve fibers are unmyelinated, and the ratio of unmyelinated to myelinated fibers is 4:1. One nonmyelinating SC is normally associated with many unmyelinated axons, while one myelinating SC is associated with only one myelinated axon. There is a short region, about $1 \mu \mathrm{m}$ in length, between two neighboring SCs called the node of Ranvier, where there is no myelin sheath. In nodes of Ranvier there are many sodium ion channels that are involved in the propagation of action potential in a process called saltatory 
conduction [2,9]. The conduction of myelinated fibers depends on axonal diameter, thickness of myelin sheath, and the length of the internodes. The conduction in unmyelinated nerve fibers is relatively slower than in myelinated fibers [10].

There are 4 types of Schwann cells. SCs associated with unmyelinated axons are called nonmyelinating SCs or Remak cells and are found in autonomic and sensory nerves. Myelinating SCs are associated with larger axons. Perisynaptic SCs play an important role in connecting nerve terminals with the peripheral tissue. Satellite SCs are associated with the neuron cell body and keep the cell body units separated [11]. A special type of Schwann cells is repair SC. This type of SC is transformed from the normal myelinating and nonmyelinating $\mathrm{SC}$ in conditions of nerve injury $[6,12]$

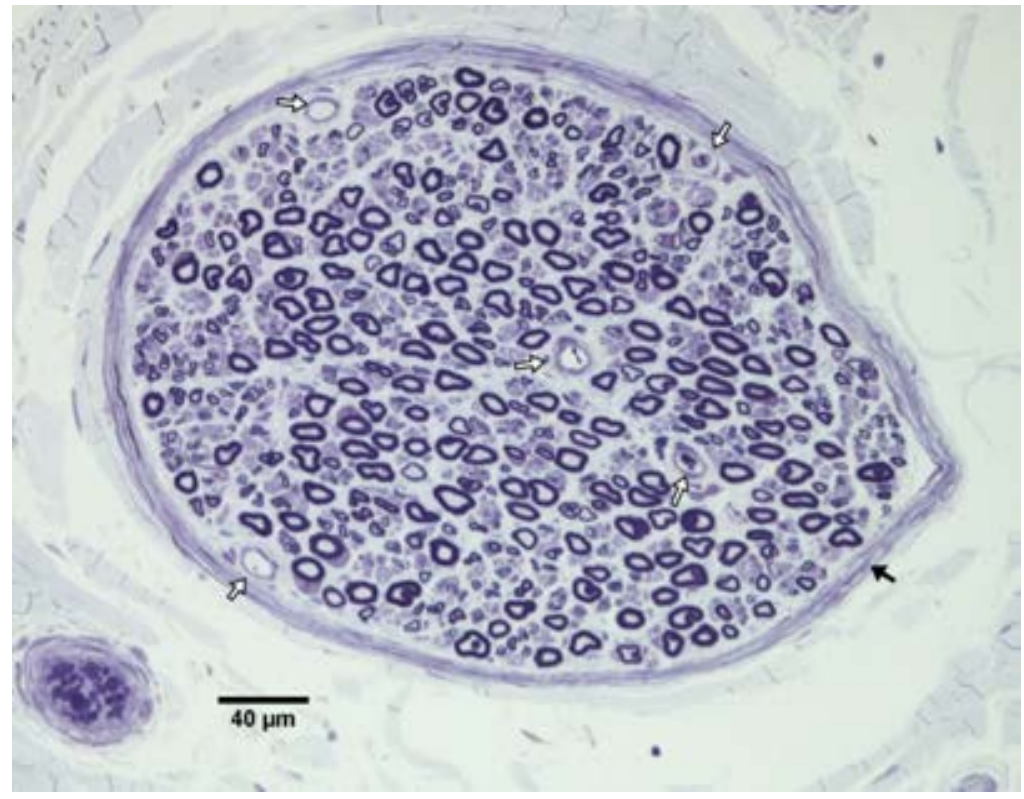

Figure 1. Fascicle in the human sural nerve shows myelinated fibers and blood vessels (white arrows) in the endoneurium surrounded by perineurium (black arrow). Semithin cross section stained with toluidine blue. Picture courtesy of Kristin Samuelsson, Karolinska institute.

\section{Nerve injury and regeneration}

Different types of injury occur in peripheral nerves. Neurapraxia is usually a compression injury that causes temporary impairment of sensory and motor functions. Axonotmesis is a division of the axon, while the nerve sheath remains intact. Neurotmesis results when the whole nerve trunk is damaged, for example by transection [13]. Following nerve injury a degradation process, known as Wallerian degeneration, occurs [14]. In Wallerian degeneration, the nerve tissue distal to the injury site starts to degrade. Axons break down and SCs remove their own myelin sheath, and the macrophages then invade the tissue and continue removing myelin and axonal debris $[15,16]$.

After removal of myelin sheaths, SCs start to proliferate and gather together in a structure called band of Büngner which guides axonal regrowth. Compared to CNS, peripheral nerves have a better regeneration capacity after injury. This ability to regenerate is a characteristic 
of SCs. When a nerve is damaged, SCs dedifferentiate and transform to repair SCs [17, 18]. Shortly after degeneration the regeneration starts and new axon sprouts grow through the tube made by the bands of Büngner. These sprouts are known as regenerating clusters or units, and they are the histological hallmarks of the axonal regeneration (Figure 2) [19].

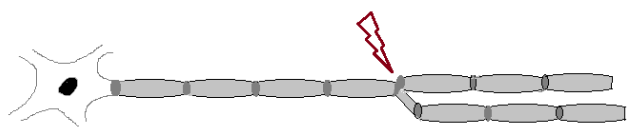

Figure 2. Following nerve injury, the distal stump undergoes Wallerian degeneration, then regenerated axon sprouts grow from the proximal stump toward the target organ.

An injury to the nerve affects protein expression in the neurons and Schwann cells. The myelin protein zero (MPZ), myelin basic protein (MBP), and myelin associated glycoprotein (MAG) are downregulated. Neurotrophic factors such as nerve growth factor (NGF), brain-derived neurotrophic factor (BDNF), glial-derived neurotrophic factor (GDNF), neurotrophin-3 (NT3), and vascular endothelial growth factor (VEGF) are upregulated [6, 20]. Growth associated protein (GAP-43) is upregulated in injured peripheral nerve, and in the growth cone $[21,22]$. SCs also activate innate immunity by releasing cytokines such as tumor necrosis factor $\alpha$ (TNF $\alpha$ ) and interleukin-1 $\alpha$ and $\beta$ which promote recruitment of macrophages and stimulate axonal regeneration [6].

\section{Nerve repair and reconstruction methods}

When a nerve trunk is transected it has to be directly repaired with sutures end-to-end or reconstructed with autologous nerve grafts, various nerve conduits or even nerve transfers depending on the length of the gap between the proximal and distal nerve ends. Many factors, such as age, time after injury, proximity of the lesion to distal targets, vascular injury, and the methods used to cover the nerve gap affect the recovery of nerve injury.

Different surgical methods used to reconstruct a nerve gap:

1) Autologous nerve grafting (autograft): a segment from another nerve of the patient (mostly the sural nerve) is used to bridge the gap. Autografts are successful in $50 \%$ of clinical cases. This method is considered the gold standard for nerve reconstruction, and it has many advantages; it supports the injured nerve with neurotrophic factors and viable SCs, and it is a non-immunogenic procedure. It also has disadvantages, including sensory loss and neuroma formation at the donor site. Because sensory and motor nerves have nerve fibers of different size, a problem of mismatch arises. Another disadvantage is that it takes a long time for the nerve to regenerate since the axons and SCs of the autograft itself need to degenerate and be removed before regeneration $[23,24]$.

2) Nerve transfer: a branch of a redundant donor nerve is transferred to a distal denervated nerve. The transfer supports the more crucial denervated target, and it may cause loss of function of the donor nerve. According to Leechavengvongs et al. 
(2003) and Merrell et al. (2001), nerve transfer results in good functional recovery $[25,26]$.

3) End-to-side coaptation: this method is used when the proximal stump is not available. The injured distal stump is connected to the side of a donor nerve. This method causes injury to the donor nerve itself. Bontioti et al. (2005) evaluated this method in rats by connecting radial or median/ulnar nerves to the side of the musculocutaneous nerve and the estimated functional recovery was about $60-70 \%$ [27].

4) Nerve conduit: a synthetic or biological material is used to bridge the gap between proximal and distal nerve segments. This method works well clinically in short gaps (less than $3 \mathrm{~cm}$ ). It requires administration of neurotrophic factors to facilitate nerve regeneration. It bridges nerve gaps without causing damage to the donor nerve. The downside of the nerve conduit is that it does not work in large nerve gap as autograft (more than $3 \mathrm{~cm}$ ). Another limitation is that functional recovery is poor [23, 24].

5) Nerve allograft: transplant of a nerve from a donor individual to a recipient patient (different person) in case of large damage of the nerves. The surgery requires administration of immunosuppressors [28].

Advances in microsurgery have improved the repair and reconstruction of injured nerves, but functional recovery is still not achieved at a satisfactory level and new approaches should be considered. Improving axonal regeneration is the easiest part of nerve repair, and the main obstacle is mismatched innervation and functional recovery.

\section{Diabetic neuropathy}

Diabetic neuropathy (DN) is a common complication of diabetes mellitus affecting around $66 \%$ of patients with type 1 diabetes and $59 \%$ of patients with type 2 diabetes [29]. In 2010 the number of people affected by diabetic neuropathy was 285 million worldwide, and this number is estimated to reach 439 million in 2030 [30].

Symptoms of diabetic neuropathy vary depending on the nerves affected, and may include numbness, loss of sensation, tingling, pain and allodynia, and muscle weakness [31, 32].

Diabetic neuropathy is not a single disease, but a wide range of diseases and can be classified according to the number, and type or location of the affected nerves. Diabetic neuropathy can either be diffuse or focal. Focal neuropathy, also called mononeuropathy, affects a single nerve, results in acute symptoms, and is less common than diffuse neuropathy. Compressive neuropathies in diabetic patients, like carpal tunnel syndrome (CTS), are examples of focal neuropathy; symptoms include paresthesia, numbness, pain, and muscle weakness $[32,33]$ and can successfully be treated in patients with type 1 and 2 diabetes [34].

Diffuse or polyneuropathy affects many nerves and includes diabetic sensorimotor polyneuropathy (DPN), diabetic autonomic neuropathy, and diabetic lumbosacral radiculoplexus neuropathy (DLRPN). DPN is characterized by loss of sensation of both small fibers (pain, temperature) and large fibers (vibration, touch, and proprioception). It affects feet and hands and can end with amputation $[32,35]$. 
Diabetic autonomic neuropathy (DAN) affects autonomic nerves, which innervate internal organs, like the heart, urogenital organs, blood vessels, and the gastrointestinal tract. Symptoms of (DAN) can be orthostatic hypotension, erectile dysfunction, gastroparesis and silent myocardial ischemia [36]. DLRPN, also known as proximal neuropathy, affects only $1 \%$ of diabetic patients, and is characterized by unilateral symptoms in hips and thighs. Symptoms include pain, muscle weakness, and sensory loss [37, 38].

Diabetic neuropathy affects sensory and autonomic nerve fibers more than motor fibers; this is because the cell body of sensory nerves is located in DRG and the blood nerve barrier (BNB) is leaky in this area allowing toxins to enter and cause damage to the cells [39, 40]. In addition, the sensory and autonomic nerve fibers are either unmyelinated or have a thin myelin sheath which makes them more vulnerable [40].

The pathogenesis of diabetic neuropathy is unknown. Hyperglycemia is considered as the major risk factor, and other risk factors include; hypertension, hypercholesterolemia, age, genetics, duration of diabetes, obesity, alcohol consumption, and smoking. There are many hypotheses meant to explain the pathogenesis of diabetic neuropathy (Figure 3 ). One is the activation of polyol pathway. It is known that the uptake of glucose by nerve cells as well as cells of the kidney and retina is not insulin dependent. In patients with diabetes the high level of glucose in blood causes hyperglysolia inside these cells. The excess amount of glucose enters the polyol pathway where glucose is reduced to sorbitol by aldose reductase (AR) then sorbitol is oxidized to fructose by sorbitol dehydrogenase (SDH) (Figure 4). This leads to depletion of NADPH and NAD in the cells, and also to the accumulation of sorbitol, which is not able to cross the cell membrane and therefore causes intracellular hyperosmolarity leading to cell death [35, 41].

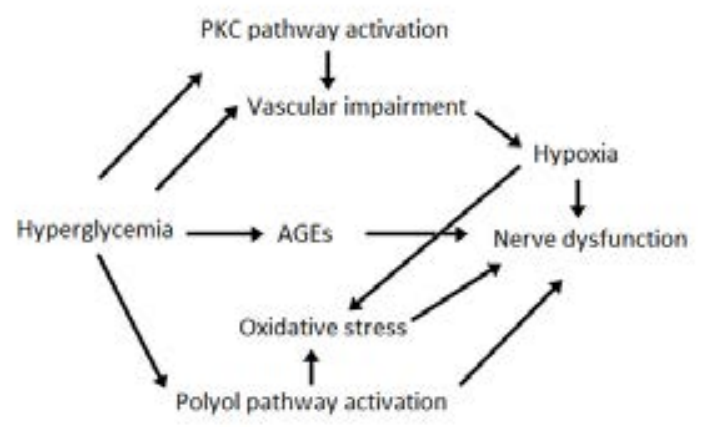

Figure 3. Hypothetical mechanisms of peripheral neuropathy in diabetic patients. Hyperglycemia activates different mechanism that can damage the peripheral nerve.

Scientists have suggested that hypoxia due to microvascular damage in peripheral nerves contributes to development of DN [31, 42, 43]. Formation of advanced glycation end products (AGEs) and activation of protein kinase $\mathrm{C}(\mathrm{PKC})$ pathway can also contribute to 
DN. Activation of the PKC pathway causes, for example, vascular changes like basal membrane thickening and endothelial cell proliferation, which lead to hypoxia [32, 40, 41].

Oxidative stress contributes to development of diabetic neuropathy [44]. Hyperglycemia leads to accumulation of reactive oxygen species (ROS) in mitochondria, causing damage to it, which consequently leads to neuropathy [35, 41].

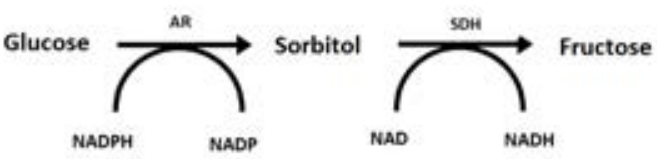

Figure 4. In the peripheral nerve, the accumulated intracellular glucose enters the polyol pathway. Aldose reductase (AR) reduces glucose to sorbitol, and sorbitol dehydrogenase (SDH) oxidizes sorbitol to fructose.

Diagnosis of diabetic neuropathy is based on case history, physical examination, laboratory blood tests for hyperglycemia, nerve conduction study (NCS), electromyography (EMG), cerebrospinal fluid (CSF) evaluation, and nerve biopsy. NCS shows decreased sensory and motor amplitudes, and slow conduction velocity. The best prevention for DN is strict control of blood glucose. DN is treated with limited success by antioxidants, aldose reductase inhibitors, neurotrophic factors, and immunoglobulin for DLRPN patients [29, 45]

\section{Chronic idiopathic axonal polyneuropathy}

The pathogenesis of one third of neuropathy cases is unknown [46]. Chronic idiopathic axonal polyneuropathy (CIAP) is a common disease in elder people in their 60s with unknown etiology $[47,48]$. The symptoms are mainly sensory affecting small nerve fibers, and they include numbness, pins and needles, coldness, tightness, muscle cramps, unsteadiness, and muscle weakness [47]. Risk factors that contribute to development of CIAP include hypertension, impaired glucose tolerance, obesity, hypercholesterolemia, and environmental toxins [47, 49-51]. All these risk factors cause oxidative stress [46].

CIAP is diagnosed by slowly progressive distal symmetric sensory or sensorimotor polyneuropathy [52]. NCS shows reduced amplitude [46], EMG examination shows abnormalities, laboratory tests show normal values, and skin biopsy confirms the diagnosis of CIAP by evaluation of density and structure of epidermal nerve fibers $[46,52]$. Erdmann et al. (2010) found that $69 \%$ of CIAP patients have pain [52]. The number of people suffering from CIAP is expected to increase due to an increasing older population. 


\section{Inflammatory neuropathy}

\section{Chronic inflammatory demyelinating polyneuropathy}

Around $10-20 \%$ of all cases of chronic neuropathies are diagnosed as chronic inflammatory demyelinating polyneuropathy (CIDP) [53]. CIDP is an immune-mediated inflammatory disease characterized by symmetrical weakness of muscles, macrophagemediated demyelination, and malfunction of sensory nerves. Symptoms include impaired sensation, absent tendon reflexes, reduced nerve conduction velocity, prolonged distal latencies, and temporal dispersion [54, 55]. Symptoms evolve over several months and are usually related to both sensory and motor nerves [56]. The disease may cause disability in about $50 \%$ of the patients [53]. CIDP is diagnosed by clinical symptoms, high protein levels in CSF, NCS revealing a demyelinating process, and sural nerve biopsy for detection of demyelination and inflammation [54, 56]. Histopathology of CIDP shows primary demyelination, onion bulbs formation, which is a hallmark of repeated demyelination and remyelination, and macrophages with granular debris [56]. Macrophage processes penetrating the basal lamina of myelinated fibers are the hallmark of primary demyelination in CIDP and Guillain-Barré syndrome (GBS). Macrophages attack nerve fibers at the node of Ranvier [56]. It is still unknown why the immune system attacks nerve fibers in CIDP. CIDP is treated effectively by corticosteroids and intravenous immunoglobulin administration $[53,56,57]$.

\section{Vasculitic neuropathy}

Vasculitis, which affects only peripheral nerves, is known as nonsystemic vasculitic neuropathy (NSVN) to distinguish it from systemic vasculitis, which can affect blood vessels in peripheral nerves among other tissues [58, 59]. In vasculitic neuropathy the immune system attacks the blood vessels of peripheral nerves causing ischemic damage; the cause is still unknown. The disease can be primary or secondary to other diseases such as rheumatoid arthritis, systemic lupus erythematosus, Sjögren's syndrome, systemic sclerosis, dermatomyositis, inflammatory bowel disease, and infectious diseases [58, 59]. Histopathology shows infiltered inflammatory cells, fibrinoid necrosis, endothelial degeneration, degeneration of vascular smooth muscle cells, and acute thrombosis [59]. There are many classifications for vasculitic neuropathy, but generally it can be divided into two classes depending on the size of the blood vessels affected in the nerve; large arteriole vasculitis, and microvasculitis [58]. Patients with vasculitic neuropathy suffer from painful sensorimotor neuropathy, and NCS shows reduced amplitude, while conduction velocity is normal or mildly reduced, and normal or slightly prolonged distal latency, which are all signs of axonal degeneration [59,60]. The disease shows acute or subacute onset, and it causes weight loss and fever in most of the cases [58, 60]. Vasculitic neuropathy is diagnosed by clinical examination, NCS, laboratory test, and biopsy. Corticosteroids are used to treat the disease [58-60]. 


\section{Autophagy}

Autophagy is a cellular process preserved in all eukaryotic cells used to recycle damaged organelles and proteins. It maintains homeostasis, regulates immunity, prevents neurodegeneration, suppresses tumor, and in time of starvation it supplies cells with amino acids recycled from degraded proteins [61]. Three type of autophagy are well described; macroautophagy, microautophagy, and chaperon mediated autophagy (CMA) [62]. Here I exclusively describe macroautophagy (hereafter called autophagy).

The autophagy process is activated by starvation, immune signals, cell stress, hormonal stimulation, infectious diseases, and drugs, like rapamycin and dopamine. Inhibitors of autophagy include diseases, like cancer, neurodegenerative disorders, and infectious diseases. Other inhibitors of autophagy pathway are aging, protease inhibitors, and drugs like bafilomycin, chloroquine, 3-methyladenine, and wortmannin [63, 64].

When activated, autophagy starts with a process called nucleation; a pre-autophagosomal structure (PAS) is formed and then a process of elongation of PAS starts. A double layer membrane called phagophore starts to form around the proteins or organelles to be degraded until it completely encapsulates them and forms a structure called an autophagosome in a process named maturation. The autophagosome then merges with a lysosome in a process called fusion, and the content of the autophagosome degrades with enzymes of the lysosome $[62,65]$ (Figure 5).

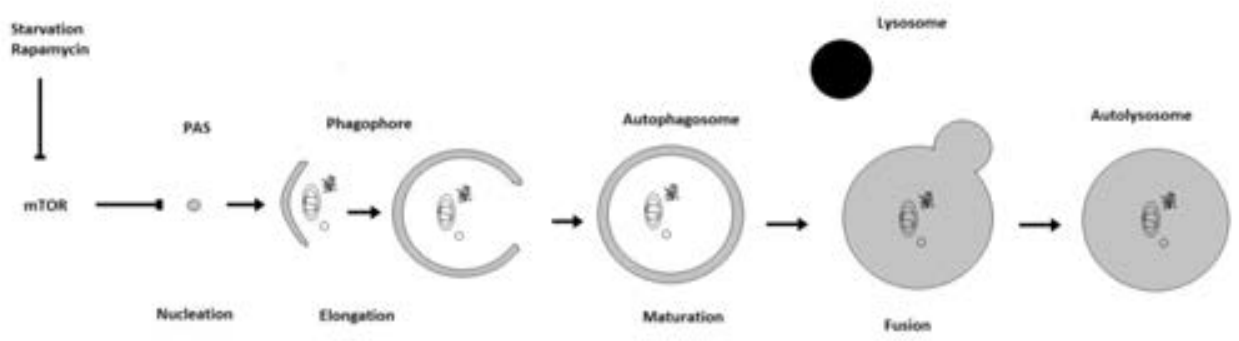

Figure 5. The autophagy process starts by inhibition of mTOR. Phagophores, a double layer membrane, enclose damaged proteins and organelles, and transport them in autophagosome to fuse with a lysosome (autolysosome) for degradation.

More than 40 proteins are known to regulate autophagy. These proteins are called autophagy proteins (ATGs), and they are evolutionary conserved from yeast to mammals. Activation of autophagy starts by inhibiting mammalian target of rapamycin (mTOR). Inhibition of mTOR activates ULK1/ATG1, which in turn activates PI3 kinase, which initiates the nucleation [62, 66, 67]. Microtubule-associated proteins 1A/1B light chain 3B (LC3/ATG8) is an important autophagy protein, and it has two isoforms. ProLC3 is cleaved at C-terminal by Cysteine protease (ATG4) to form LC3-I, which is a soluble protein and then a phospholipid called Phosphatidylethanolamine (PE) binds to LC3-I by ATG7 to form LC3-II which is membrane protein and plays an important role in elongation of the double layer membrane $[62,65,68]$. LC3-II is the only know marker of an autophagosome. Autophagosome-lysosome fusion requires involvement of several proteins such as 
coordinated lysosomal expression and regulation (CLEAR) network and transcription factor EB (TFEB) [69, 70].

Autophagy receptors are proteins that bind to both LC3-II and the ubiquitinated proteins to be degraded, and ensure that the damaged proteins are localized inside the autophagosome. Many autophagy receptors have been identified, among them are SQSTM1/p62, NBR1, OPTN, NIX [71-73].

Autophagy can be divided into two types depending on the protein cargo to be degraded; bulk autophagy and selective autophagy. In bulk autophagy, the proteins, which are no longer needed, are non-selectively sequestered and introduced to lysosomes, and this usually happens during nutrient starvation. In selective autophagy, the autophagy receptors bind selectively to specific organelles and proteins. Examples of selective autophagy are mitophagy (mitochondria autophagy) [74], pexophagy (peroxisome autophagy) [75], xenophagy (autophagy of intracellular pathogens) [76], and myelinophagy (myelin autophagy) [77].

\section{Autophagy and diseases}

Malfunction of autophagy machinery has been connected to many diseases. In cancer, which was the first disease found to be associated with autophagy impairment, many autophagy proteins are found to be downregulated in some types of cancer, and upregulated in other types [64]. The role of autophagy in cancer depends on tumor developmental stage. In the early stages of cancer, autophagy plays a protective role against the tumor, and at a later stage tumor cells recruit autophagy mechanism for their own survival [78].

Neurons are differentiated non-dividing cells, and maintenance of homeostasis is very important for cell survival. In the nervous system, aggregation of misfolded proteins causes neurotoxicity, and leads to development of many neurodegenerative diseases, like Alzheimer's, Parkinson's, and Huntington's diseases. In Alzheimer's disease, the autophagy pathway was found to be impaired and autophagic vacuoles were accumulated in the cell $[79,80]$. Autophagic vacuoles are rarely seen in healthy neurons. Yu et al. (2005) have reported that amyloid $\beta$ generates and accumulates in autophagic vacuoles, and suggested that $\mathrm{A} \beta$ formation is associated with impaired autophagy [81]. In Parkinson's disease, accumulation of $\alpha$-synuclein in the neurons of substantia nigra forms Lewy bodies and causes cell death. Cuervo et al. (2004) found that wild type $\alpha$-synuclein is degraded by CMA, but the mutant $\alpha$-synuclein block the degradation process and accumulate in the cell [82]. Neuronal cell death caused by accumulation of $\alpha$-synuclein was associated with accumulation of autophagic vacuoles, which can be due to failure of autophagosome lysosome fusion [80]. Huntington's disease is a neurodegenerative disease caused by aggregation of mutant huntingtin (HTT) protein in the striatum, which controls the movement of the body, leading to motor control disability that characterizes the disease. Ravikumar et al. (2004) showed that activation of autophagy by rapamycin decreases the accumulation of HTT and neurodegeneration in mice with Huntington's disease [83]. Inhibition of autophagy increases aggregation of HTT [80], which shows the importance of autophagy as cytoprotective mechanism against neurodegenerative diseases.

Many studies have investigated the role of autophagy in the CNS, but less studies have been done concerning the process in PNS. Piao et al. (2004) found that autophagy plays a role in 
clearing the degenerated axon in the sciatic nerve of rats [84]. In our lab, autophagy structures were observed in the peripheral nerves of diabetic rats [85]. However, no research has been done to investigate if autophagy machinery exists in the human PNS, and whether autophagy plays a role in peripheral neuropathy. 


\section{AIM}

The general aim of the research was to investigate the role of autophagy in peripheral neuropathy.

\section{Specific aims}

1. To find out if autophagy machinery exists in human peripheral nerves, and if so, to investigate whether there is any correlation between autophagy and neuropathy in diabetes.

2. To evaluate autophagy-related structures in peripheral nerves of patients with CIAP and inflammatory neuropathy. In addition, to study the presence of microangiopathy in those patients.

3. To investigate the effect of autophagy activation on axonal regeneration, to construct a biological nerve conduit to guide axonal regeneration, and to make proteome profile of transected nerve after reconstruction in GK rats. 


\section{METHODS}

Different methods were used to accomplish the aim of this study. In this section, I summarize these methods, and for more details please refer to the methods section in each paper.

\section{Nerve conduction study}

Nerve conduction study is a method used by clinicians and researcher to study the pathology of the peripheral nerves. NCS is used to evaluate the conduction of nerve signals in the nerve, and helps to understand the type of lesion and its location along the nerve. NCS is performed by electrically stimulating the nerve and recording the compound muscle action potential (CMAP) of the innervated muscle; in case of the motor nerve. CMAP represents the summation of the voltage response of muscle fibers' action potential. In sensory nerves, the sensory nerve action potential (SNAP) is recorded by electrically stimulating a sensory nerve and recording the nerve action potential at another place along the nerve [86, 87]. NCS can be performed orthodromically or antidromically, depending on the direction of the nerve signal. In the orthodromic approach, the nerve action potential is transferred in the physiological direction, while in the antidromic the action potential is transferred against the physiological direction of the nerve signal [88].

When a nerve is electrically stimulated, an action potential propagates in both directions. The signal that propagates distally shows the amplitude of CMAP or SNAP, while the signal that propagates proximally depolarizes the axon hillock and fires an action potential which appears at longer latency as an F-wave. This F-wave allows investigation of the proximal segment of the nerve. The latency shows the time between the stimulation and the response. Nerve conduction velocity is measured by stimulating the nerve at two points on the nerve, calculating the time signal traveled between the two points, then dividing the distance by the time $[86,89]$.

Generally, prolonged latency indicates demyelination, while reduced amplitude indicates axonal loss. Temporal dispersion happens when the action potential of individual axons travels at different speeds and arrives at different times, which causes loss of CMAP and SNAP amplitude [86, 89]. NCS results were used as selection criteria for patients in papers 1 and 2.

\section{Human nerve biopsies}

Biopsies from the posterior interosseous nerve of patients with diabetic peripheral neuropathy who underwent carpal tunnel release surgery, and biopsies from patients with CTS without diabetes were used as controls (paper 1). Sural nerve biopsies from patients with CIAP and inflammatory neuropathy (CIDP and vasculitic neuropathy), and sural nerve biopsies from controls were used (paper 2). 


\section{Electron microscopy}

Electron microscopy (EM) is a very useful method to study the structure of peripheral nerve tissue and was the tool used to detect autophagy for the first time in 1950 [90]. EM is considered as the gold standard technique to study autophagy, and it is the only method that can show the morphology of autophagy structures in high resolution. It is an accurate and reliable method for identification and quantification of autophagy structures. The disadvantages of EM are that it does not detect autophagic flux; autophagy is a dynamic process, and one should quantify the turnover of degraded proteins rather than just presence of autophagic proteins. Identification of autophagy structures by using EM requires experience and time.

I have used transmission electron microscopy (TEM) in papers 1 and 2 to study the pathology in the posterior interosseous and sural nerves in patients with DN, CIAP, and inflammatory neuropathy. I have also used TEM to identify autophagy structures and quantify them by calculating their density (number per $\mathrm{mm}^{2}$ ) in nerve fascicles.

\section{Animal models and nerve injury}

The Goto-Kakizaki (GK) rats are non-obese Wistar rats that develop type 2 diabetes mellitus. GK rats have many characteristics similar to those in type 2 diabetic human patients, such as decreased insulin response to glucose, decreased glucose oxidation, and increased lipid profiles. The blood glucose level in GK rats is $50-55 \%$ higher than that in healthy Wistar rats [91].

A sciatic nerve injury in rodents has been used as a model to study nerve regeneration for a long time. The sciatic nerve contains sensory, motor, and autonomic nerve fibers, and anatomically is easily accessed during surgery, which makes it the nerve of choice in peripheral nerve studies [13].

In order to investigate peripheral nerve injury and repair, rats are the preferred models because they show similarities in injury response to human response and also have similar microscopic structures.

I used GK rats in paper 3. The sciatic nerve of the left hind limb of the rats was transected and reconnected with a collagen nerve conduit (CNC) containing either nerve growth factor (NGF), or NGF + rapamycin (autophagy activator). After 1, 4, and 8 weeks, rats were euthanized and samples were collected from distal and proximal stumps of the injured nerves, and the CNC.

\section{Immunohistochemistry}

Immunohistochemistry (IHC) is considered as one of the most powerful techniques to study the structure and composition of cells and tissues. IHC is used to study autophagy by detecting autophagic proteins (ATGs), like ATG8/LC3, ATG4, ATG9, ATG7, BECN1, AMBRA1, and autophagic receptors like SQSTM1/p62, NIX, NBR1, OPTN and others. There are many methods to monitor autophagic flux [90] one of which is to detect and 
quantify LC3-II (marker of autophagosome), or to quantify LC3 and one of the autophagy receptors such as (p62), which I have used in the research for paper 3 [90].

In paper 3, I used immunohistochemistry to detect, localize, and quantify proteins in nerve samples from GK rats 1, 4, and 8 weeks after injury. Samples from proximal and distal stumps of the injured sciatic nerve of GK rats were fixed, cryosectioned, and immunostained with antibodies against autophagy protein (LC3), autophagy receptor (p62), Schwann cell marker (S-100), and neurofilament marker (NF) (Figure 6). The confocal microscope was used for imaging, and ImageJ was used for image analysis.

\section{Mass spectrometry}

Mass spectrometry-based proteomics is a powerful technique to study the whole proteome of cells, tissues, and organisms. It helps to understand the molecular mechanisms of biological processes, pathogenesis of diseases, and it helps researchers to discover new drug targets. Liquid chromatography tandem mass spectrometry (LC-MS/MS) is used to study proteins in complex mixtures. Two approaches are used in mass spectrometry; top-down proteomics, in which the whole proteins are used for analysis, and bottom-up proteomics, in which the proteins are digested to peptides before analysis in the mass spectrometer. The proteins are digested using enzymes like trypsin. The mass spectrometer measures mass to charge ratio $(\mathrm{m} / \mathrm{z})$ of the fragmented peptides and this value is used later for identification of peptides and proteins by searching in protein databases. In MS/MS or tandem MS, the peptide mass is measured and the peptide is then fragmented and the mass of the fragments is measured again [92].

The advantage of proteomics compared to transcriptomics is that it gives more information about the biological sample. For instance, it allows to study post-translational modifications and protein-protein interaction, which gives a better understanding of functional and biological process of expressed proteins.

In paper 3, I used (LC-MS/MS) to study the proteome of sciatic nerves of GK rats after injury in comparison with control nerves from GK rats without injury (Figure 6). Proteins were extracted from nerve samples, then digested with trypsin, and the peptides were analyzed with mass spectrometer. This method allowed us to identify and quantify the protein content of injured and non-injured nerves. 


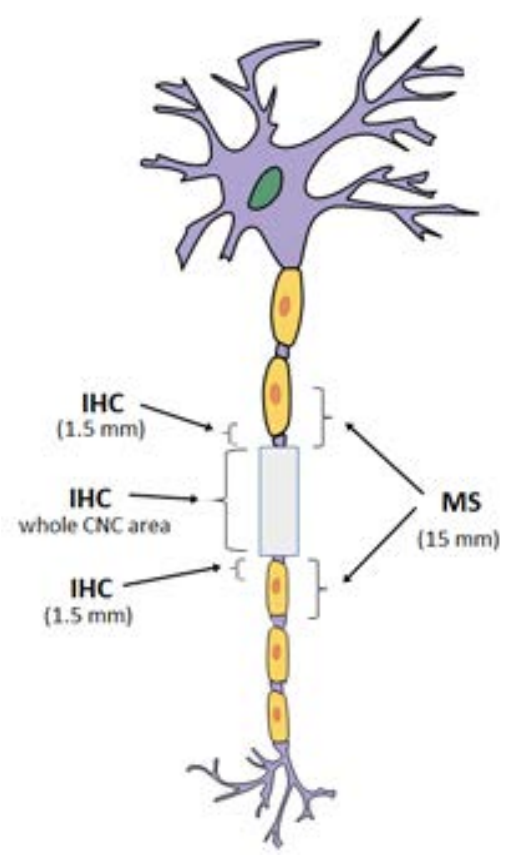

Figure 6. For immunohistochemistry (IHC) $1.5 \mathrm{~mm}$ of the nerve stumps, and sections from the whole collagen nerve conduits (CNC) were used. About $15 \mathrm{~mm}$ of proximal and distal nerve stumps were used for proteomics by mass spectrometry (MS).

\section{Bioinformatics}

Analyzing proteomics data is a great challenge since mass spectrometry produces such large amounts of data. Bioinformatics provides tools to be used in extracting meaningful knowledge of the output of the proteomics data.

There are two levels of data analysis in the field of proteomics; basic level and advanced level. At the basic level the mass spectrometry data are analyzed to identify and quantify peptides and proteins, and at the advanced level the output of the basic level is used as input in specialized databases and analyzed to produce more useful information such as information about protein functions, annotations, and biological pathways [92].

I used bioinformatics to analyze mass spectrometry data in paper 3. Proteome Discoverer and Sequest HT were used to identify proteins and Scaffold was used to quantify the proteins in the nerve samples. NCBI GO annotations and STRING database were used to classify proteins according to their functions. 
Summary of papers 


\section{SUMMARY OF PAPERS}

\section{Paper 1}

\section{Aim:}

To find out if autophagy machinery exists in human peripheral nerves, and, if so, to investigate whether there is any correlation between autophagy and neuropathy in diabetes.

\section{Findings:}

- Patients with type 1 diabetes have a significantly lower density of myelinated nerve fibers in the posterior interosseous nerve compared to controls.

- Patients with type 1 diabetes have significantly smaller myelinated and unmyelinated nerve fibers compared to both patients with type 2 diabetes and controls. Type 2 diabetic patients have smaller myelinated fibers than controls.

- Patients with type 1 diabetes have significantly larger g-ratio than both type 2 and controls.

- Type 1 diabetic patients have a higher density of unmyelinated fibers compared to controls.

- Patients with type 1 diabetes have a significantly higher density of autophagy structures than patients with type 2 diabetes.

\section{Conclusion:}

Autophagy exists in human peripheral nerves, and it is regulated differently in the nerves of patients with type 1 and type 2 diabetes.

\section{Paper 2}

Aim:

To evaluate autophagy-related structures in the peripheral nerves of patients with CIAP and inflammatory neuropathy. In addition, to study the presence of microangiopathy in these patients.

\section{Findings:}

- Patients with CIAP and inflammatory neuropathy had a lower density of myelinated nerve fibers in the sural nerve compared to controls.

- Patients with inflammatory neuropathy had smaller unmyelinated fibers than both CIAP patients and controls.

- Blood vessels of the sural nerve from patients with inflammatory neuropathy had significantly larger endothelial cell area and basal lamina area thickness (BLAT) compared to CIAP and controls.

- The number of endothelial cell profiles and periendothelial cell nuclei was significantly higher in patients with inflammatory neuropathy compared to controls. 
- The density of autophagy structures was significantly higher in patients with CIAP and inflammatory neuropathy compared to controls.

\section{Conclusion:}

Autophagy exists in peripheral nerves in different neuropathological conditions, and the density of autophagy structures is higher in neuropathic nerves.

\section{Paper 3}

\section{Aim:}

To investigate the effect of autophagy activation on axonal regeneration, to construct biological nerve conduits to guide axonal regeneration, and to make proteome profile of injured nerves in GK rats.

\section{Findings:}

- Collagen nerve conduits support and guide axonal regrowth in the transected sciatic nerve of GK diabetic rats.

- Injury to the sciatic nerve of GK diabetic rats increases LC3 and p62 levels in the first week after surgery.

- Activation of autophagy by rapamycin increases LC3 levels after injury up to 8 weeks, and decreases p62 levels up to 4 weeks of injury.

- NGF incorporated in CNC increases axonal sprouting 4 weeks after injury, but many of the regenerated axons degenerate at 8 weeks after injury.

- An injured sciatic nerve connected with CNC incorporated with NGF and rapamycin dissolved in DMSO showed significantly higher NF fluorescence intensity at 8 weeks after injury compared to non-injured control nerves.

- Rapamycin regulates proteins involved in axonal regeneration and cell survival.

\section{Conclusion:}

Rapamycin increases long-term axonal regeneration, and regulates many proteins involved in nerve regeneration. 


\section{RESULTS AND DISCUSSION}

Here, I present and discuss the main results reported in the papers included in the thesis.

\section{Paper 1}

\section{Background}

Most of the patients with diabetes mellitus suffer from peripheral neuropathy. The cause of diabetic neuropathy is unknown, and hyperglycemia is the major risk factor. Autophagy, the degradation mechanism used by a cell to remove the damaged organelles and proteins by lysosomes, has been found to be impaired in many experimental studies of neuropathies [85, 93]. To my knowledge there is no published study concerned with the investigation of autophagy in peripheral neuropathy in humans. I hypothesized that impaired autophagy in peripheral nerves of patients with diabetes contributes to the pathogenesis of peripheral neuropathy.

In this paper, I aimed to find out if autophagy machinery exists in human peripheral nerves, and if so, to investigate whether there is any correlation between autophagy and neuropathy in diabetes. I studied the pathology and autophagy in the posterior interosseous nerve of patients with type 1 and 2 diabetes mellitus.

\section{Results and discussion}

I observed signs of neuropathy in nerves of diabetic patients, and it was more severe in type 1 diabetic patients. Controls with CTS also showed signs of neuropathy. The density of myelinated nerve fibers was significantly lower in type 1 diabetic patients compared to controls $(p<0.05)$ (Figure 7). Axonal atrophy that is one of the characteristics of diabetic neuropathy (Figure 8a), as well as axonal degeneration (Figures 8b;9) and demyelination (Figure 9) was observed in nerve samples from all diabetic patients. 


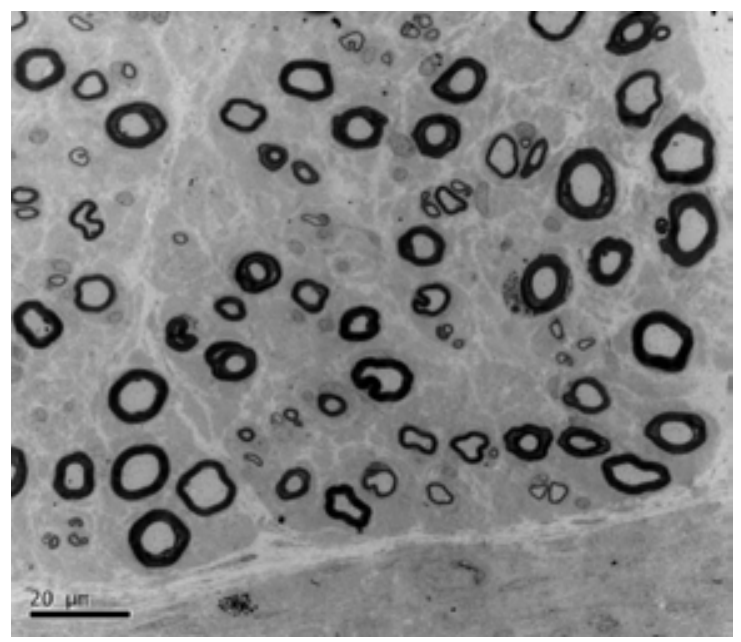

Figure 7. Low density of myelinated fibers in posterior interosseous nerve of type 1 diabetic patient. Scale bar $=20 \mu \mathrm{m}$. (electron micrograph).

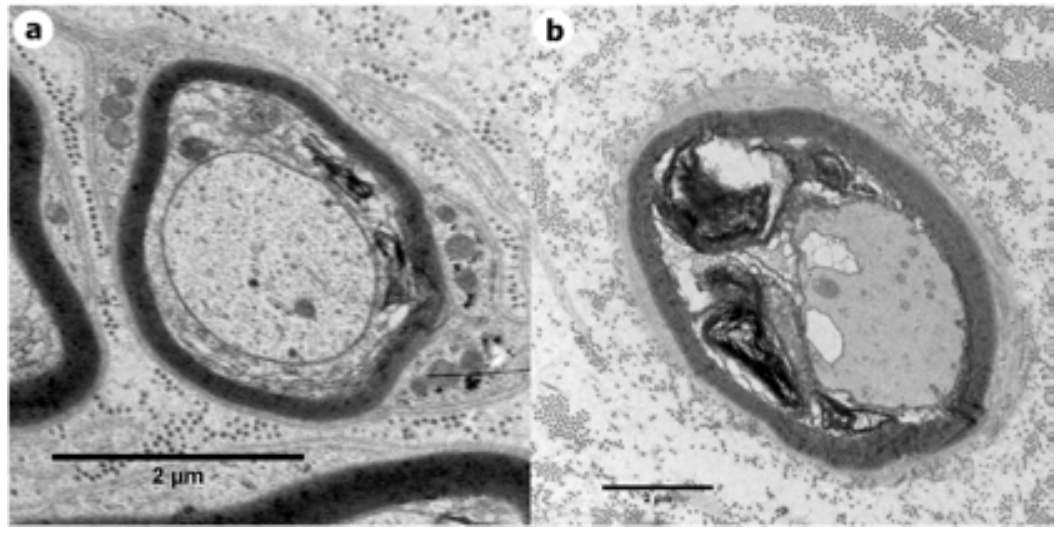

Figure 8. (a) Axonal atrophy in type 1 diabetes. (b) Axonal degeneration in type 1 diabetes. Scale bar $=2 \mu \mathrm{m}$. Human posterior interosseous nerve (electron micrograph).

Denervated Schwann cells (empty SCs) and collagen pockets occur normally in healthy axons, but they increase by age and neuropathy. I observed many denervated SCs (Figure 9) and collagen pockets (Figure 10a) in all groups, but they were observed more frequently in type 1 diabetic patients. 


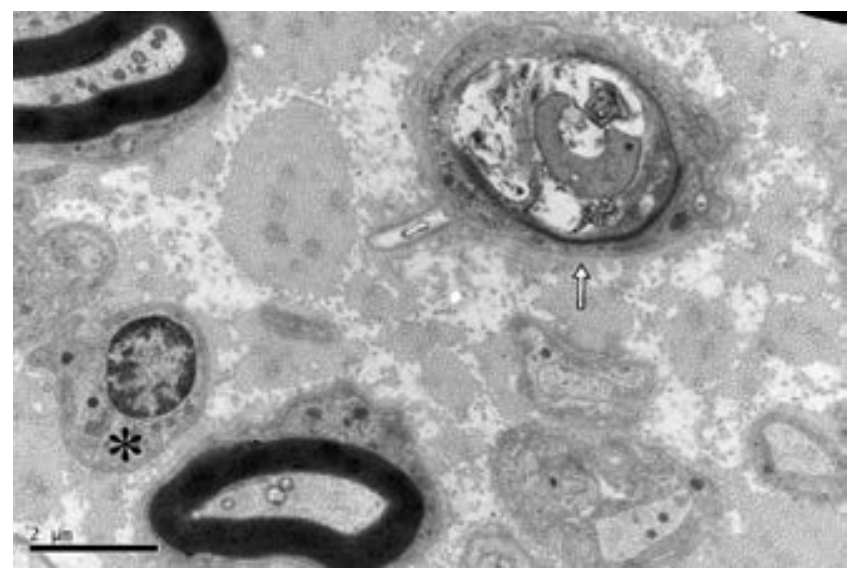

Figure 9. Axonal degeneration and demyelination (white arrow), and denervated SC (asterisk) in type 1 diabetes. Scale bar $=2 \mu \mathrm{m}$. Human posterior interosseous nerve (electron micrograph).

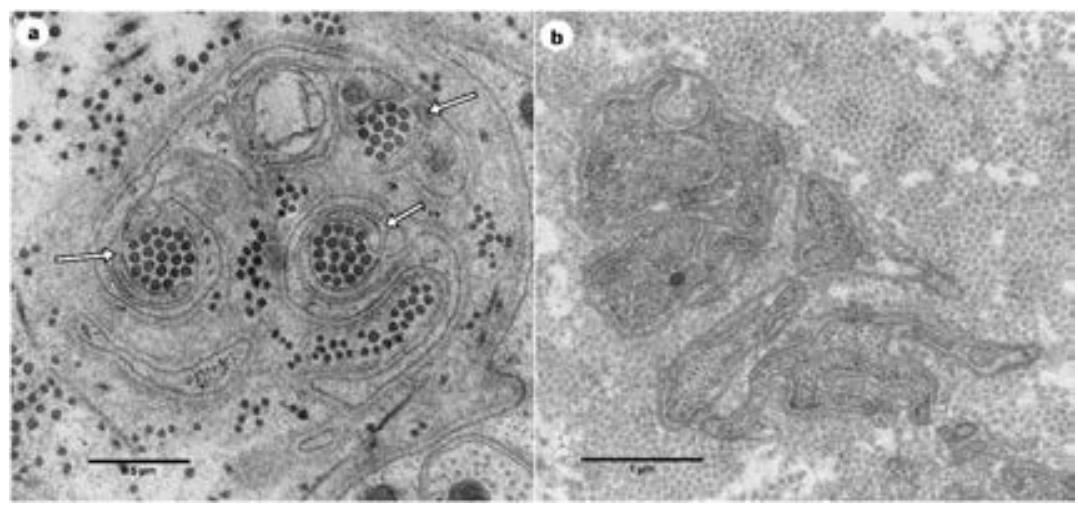

Figure 10. (a) Collagen pockets in type 1 diabetic patients (arrows). (b) Bands of Büngner in type 1 diabetic patients. Scale bar $=0.5 \mu \mathrm{m}$ in (a), $1 \mu \mathrm{m}$ in (b). Human posterior interosseous nerve (electron micrograph).

Bands of Büngner (Figure 10b), as sign of initiation of axonal regeneration, were observed in samples from diabetic patients. Reich pi granules are inclusion bodies found in myelinating SC close to the nucleus. They are normally observed in healthy axons, but their number increases with age and pathology. I have observed many Reich pi granules in nerves of diabetic patients (paper 1).

The results showed loss of large myelinated axons in patients with type 1 and type 2 diabetes. The diameter of myelinated nerve fibers in patients with type 2 diabetes was significantly smaller than that in healthy controls, and patients with type 1 diabetes had significantly smaller myelinated and unmyelinated fibers than both type 2 diabetes and controls (Figure 11). Smaller nerve fibers indicate that there was either loss of large nerve 
fibers and/or increase in small regenerated nerve fibers. I have also calculated the g-ratio, which shows the thickness of myelin sheath, by dividing axon diameter by diameter of the nerve fiber (axon + myelin sheath). The normal g-ratio in peripheral nerve is around $0.5-$ 0.7 [2] and is associated with optimal nerve conduction velocity. The larger g-ratio means thin myelin sheath, which indicate remyelination or hypomyelination, and the lower g-ratio means thick myelin sheath and occur in hypermyelination. I found that patients with type 1 diabetes have significantly larger g-ratio than both type 2 and controls. The density of unmyelinated fibers was significantly higher in type 1 diabetic patients than controls. These results could mean that there are many regenerated axons in type 1 diabetic patients.

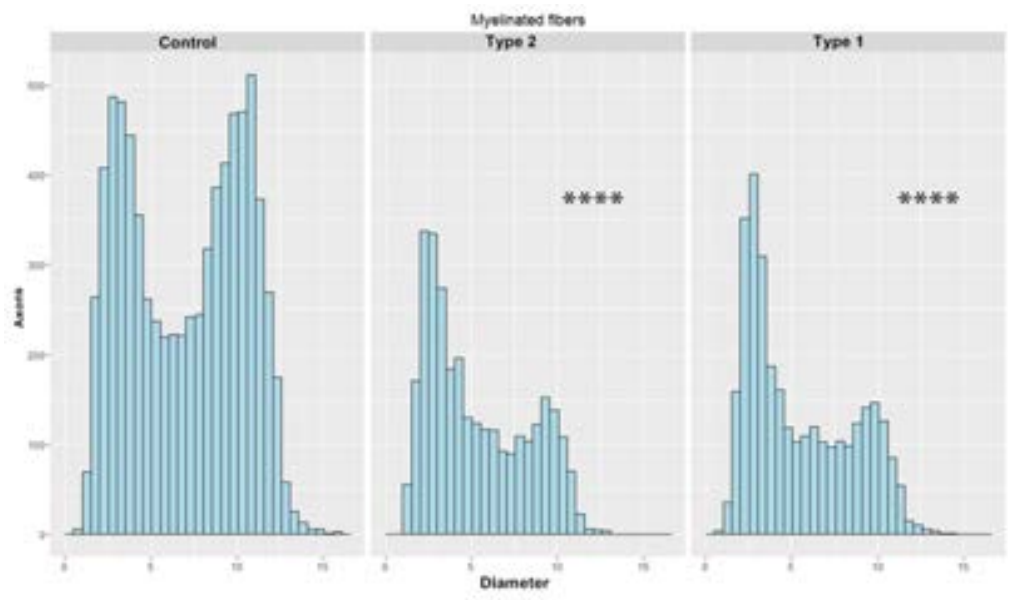

Figure 11. Histograms show the distribution of myelinated nerve fibers diameter in the posterior interosseous nerve of controls and patients with type 2 and type 1 diabetes mellitus. Significant loss of large myelinated fibers was observed in type 1 and 2 diabetes compared to controls. **** $p<$ 0.0001 .

These results, for the first time, presented ultrastructural signs of autophagy in human peripheral nerves (Figure 12). 


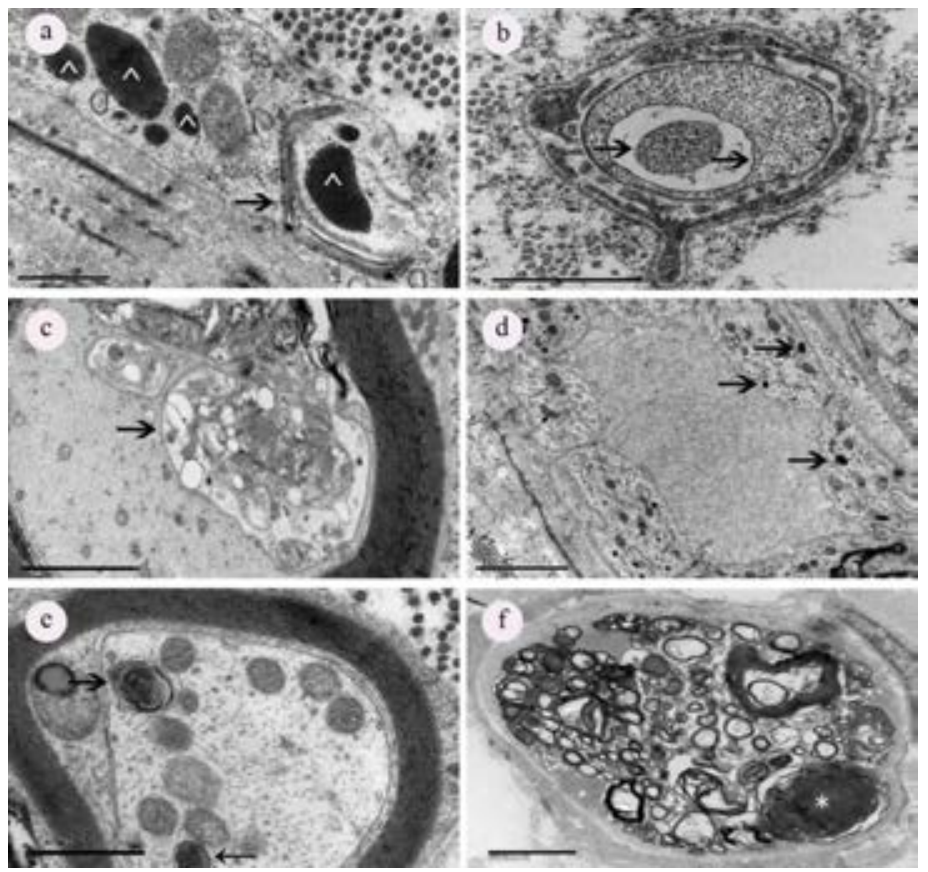

Figure 12. Autophagy structures in the human posterior interosseous nerve. (a) Phagophore (arrow) and electron dense lysosomes (arrowheads) in a fibroblast. (b) Autophagosomes in an axons, arrows show the double membrane of the autophagosomes. (c) Autophagosomes in myelinated axons. (d) electron-dense lysosomes in endothelial cells (arrows). (e) Autolysosomes in myelinated axon (arrows). (f) Autolysosomes (asterisk) and myelin ovoids in a Schwann cell. Scale bars, $500 \mathrm{~nm}(a, e), 1 \mu \mathrm{m}$ (b) and $2 \mu \mathrm{m}$ (c, d, f). (Electron micrograph).

The density of autophagy-related structures in patients with type 1 diabetes was significantly higher than in type 2 diabetes patients, and tended to be higher compared to controls $(p=0.06)$ (paper 1).

These findings show that autophagy exists in the human PNS, and the density of autophagyrelated structures was significantly higher in nerves of patients with type 1 than type 2 diabetes. The results also showed extensive signs of neuropathy in the nerves of patients with type 1 diabetes compared to type 2 . These findings suggest that autophagy is regulated differently in PNS of patients with type 1 and 2 diabetes, and this different regulation can be associated with the severity of neuropathy. The fact that type 1 diabetic patients had more autophagy structures than type 2 suggests that autophagy is either stimulated in type 1 diabetic patients and therefore the formation of phagophores and autophagosomes is increased, or that the autophagic flux is blocked downstream, for instance the fusion of autophagosome and lysosome is inhibited, which leads to accumulation of autophagy structures. A limitation of my study is that EM was the only method used to detect autophagy. Autophagy is a dynamic process and EM does not show the autophagic flux (the turnover of degraded proteins). To confirm the results of EM another method should be 
used to monitor autophagy flux in order to quantify autophagic proteins and receptors, as recommended by Klionsky et al. (2016) [90].

Autophagy has been observed in CNS in human [94] and was found to be upregulated in neurodegenerative diseases $[79,95]$. My study is the first study to investigate autophagy in PNS of humans with neuropathy.

I conclude that the density of autophagy structures correlates with the severity of neuropathy, and autophagy is regulated differently in PNS of patients with type 1 and 2 diabetes. Further studies is needed to investigate the autophagy in other nerves and peripheral neuropathy conditions other than diabetes.

\section{Paper 2}

\section{Background}

Chronic idiopathic axonal polyneuropathy (CIAP) and inflammatory neuropathies (chronic inflammatory demyelinating polyneuropathy and vasculitic neuropathy) affect millions of people globally. The etiology of these diseases is unknown. In paper 1, I showed that autophagy exists in human PNS. Furthermore, the more severe neuropathy in type 1 diabetes vs type 2 diabetes was associated with a higher density of autophagy structures in the nerves. Here, I hypothesize that autophagy impairment is involved in the development of peripheral neuropathy in patients with CIAP and inflammatory neuropathy.

In this paper, I aimed to evaluate autophagy-related structures in peripheral nerves of patients with CIAP and inflammatory neuropathy. In addition, to study the presence of microangiopathy in those patients. Samples from the sural nerve of patients with CIAP and inflammatory neuropathy were used in this study.

\section{Results and discussion}

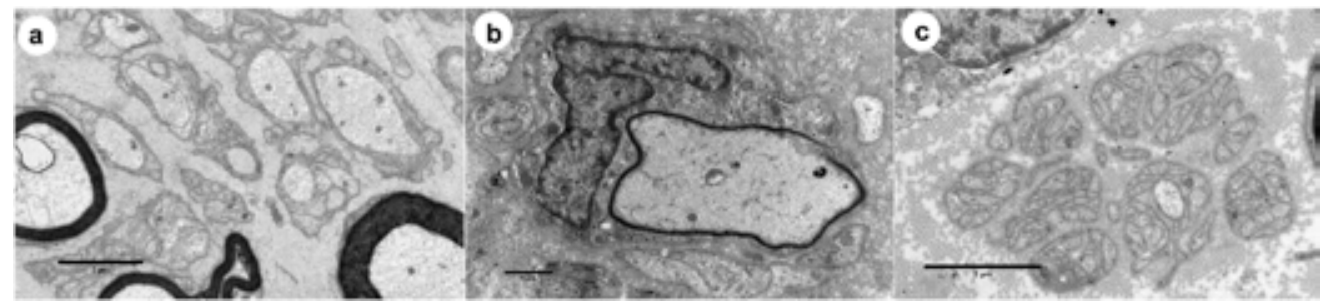

Figure 13. (a) Large unmyelinated fibers, (b) remyelinated fiber and (c) bands of Büngner. Scale bar in $(a, c)=2 \mu \mathrm{m}$, in $(b)=1 \mu \mathrm{m}$. Human sural nerve (electron micrograph).

Light and electron microscopy were used to study the pathology and autophagy in the sural nerve from patients with CIAP and inflammatory neuropathy. I observed large unmyelinated fibers (Figure 13a), collagen pockets, and bands of Büngner in all groups. Micrographs of sural nerves obtained from patients with CIAP showed sign of axonal degeneration, and regeneration. In the sural nerves of patients with inflammatory neuropathy, extensive axonal degeneration, remyelination (Figure 13b), and macrophages 
containing degradation products (Figure 14; 15) were observed. Samples from inflammatory neuropathy patients also showed signs of microangiopathy.

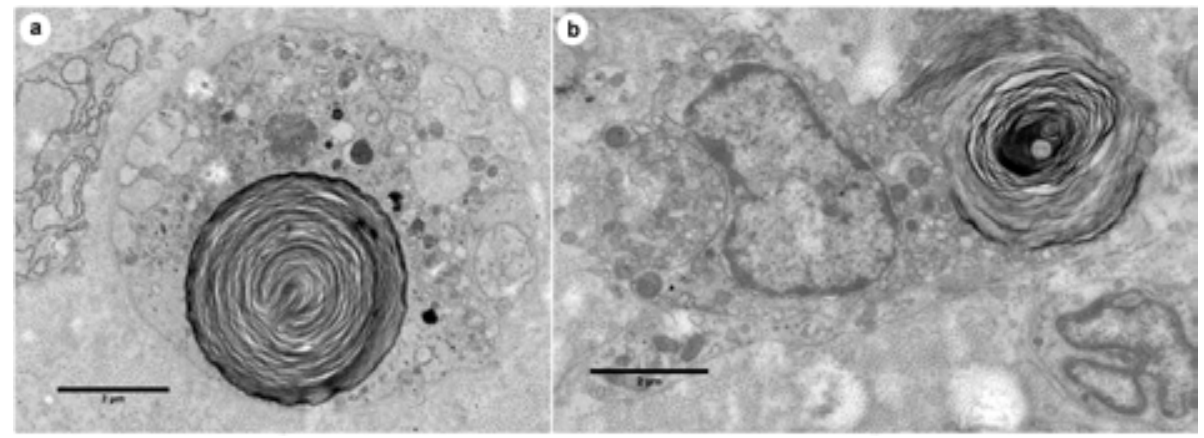

Figure 14. Myelin debris in Schwann cell (a) and macrophage (b). Scale bar $=2 \mu$ m. Human sural nerve (electron micrograph).

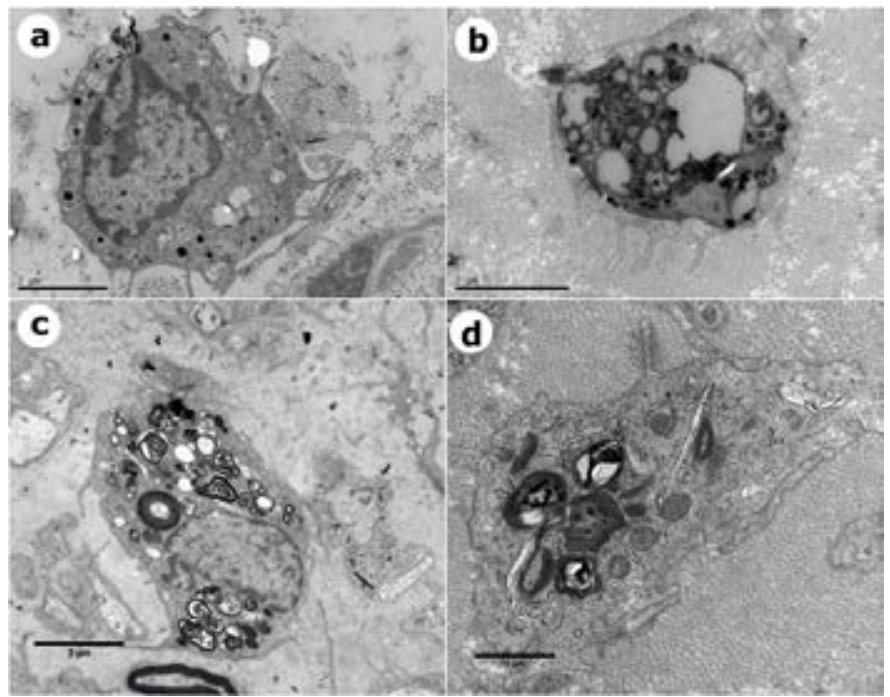

Figure 15. Macrophages in the sural nerve of patients with inflammatory neuropathy. Scale bar in $(a, b)=2 \mu \mathrm{m}$, in $(c)=3 \mu \mathrm{m}$, in $(d)=1 \mu \mathrm{m}$. Human sural nerve (electron micrograph). 
The number of large myelinated fibers was significantly reduced in the nerves of patients with CIAP and inflammatory neuropathy compared to controls (Figure 16). Patients with inflammatory neuropathy had smaller unmyelinated nerve fibers compared to patients with CIAP and controls (Figure 17). The histopathology and morphometric findings confirm the diagnostic results of NCS in CIAP and inflammatory neuropathy patients.

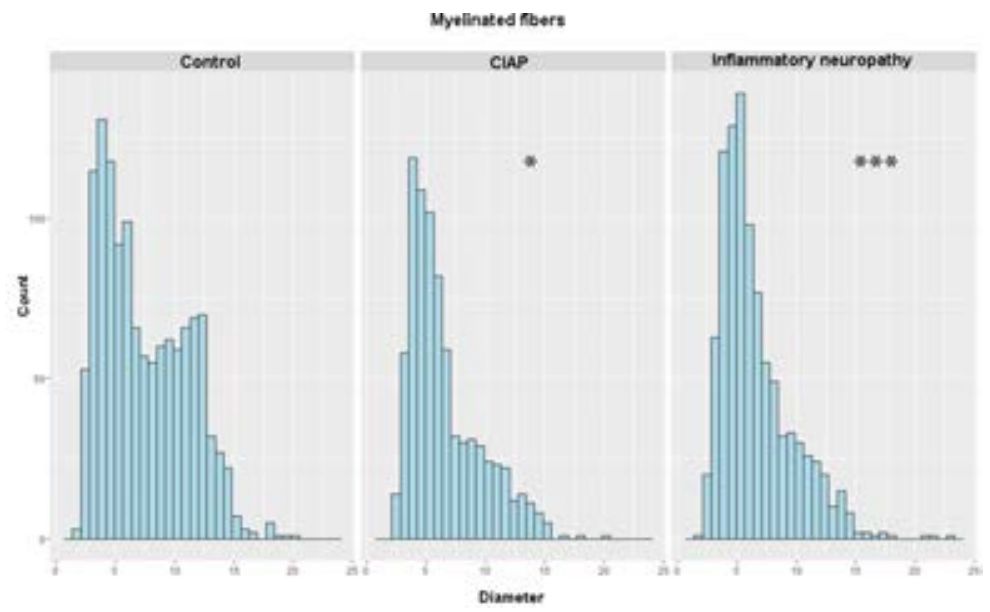

Figure 16. Histograms show that sural nerve of patients with CIAP and inflammatory neuropathy have smaller myelinated fibers compared to controls. ${ }^{*} p<0.05, * * * p<0.001$.

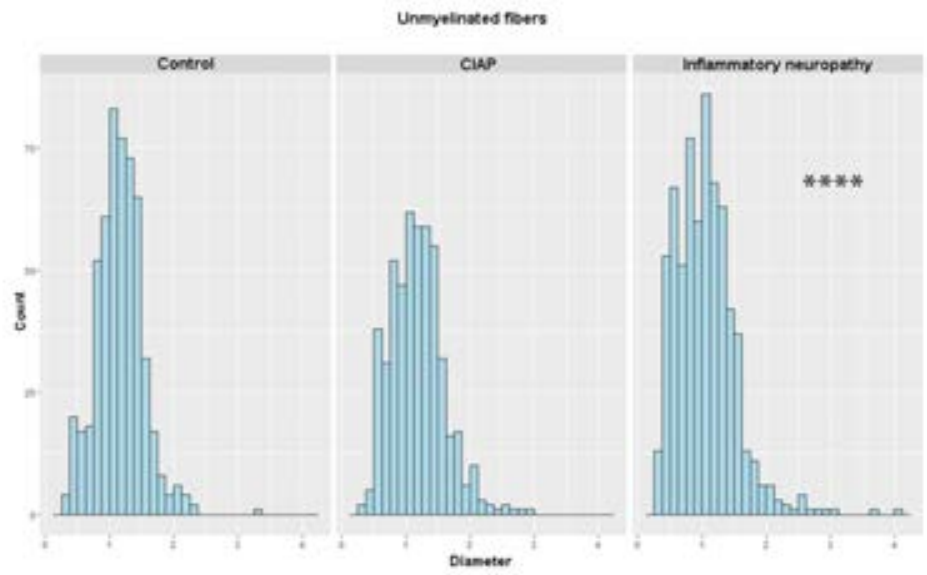

Figure 17. Histograms show that the sural nerve of patients with inflammatory neuropathy had smaller unmyelinated fibers than both CIAP and controls. ${ }^{* * * *} p<0.0001$.

We also studied microangiopathy by analyzing endoneurial blood vessels with a focus on lumen area, endothelial cell area, and basal lamina area thickness (BLAT). Endothelial cell area and BLAT were significantly larger in patients with inflammatory neuropathy compared to CIAP and controls. The numbers of endothelial cell profile and periendothelial 
cell nuclei were significantly higher in patients with inflammatory neuropathy compared to controls (paper 2).

I quantified autophagy structures in the sural nerve samples and calculated their density per fascicle area. All types of autophagy structures were observed in samples from all groups (Figure 18). However, the density of autophagy structures was significantly higher in patients with CIAP and inflammatory neuropathy compared to controls.

In CIAP patients, the density of autophagy structures in the SCs of unmyelinated fibers was found significantly higher than controls, while autophagy structures in myelinated axons were less frequent in samples from CIAP and inflammatory neuropathy compared to controls (paper 2).

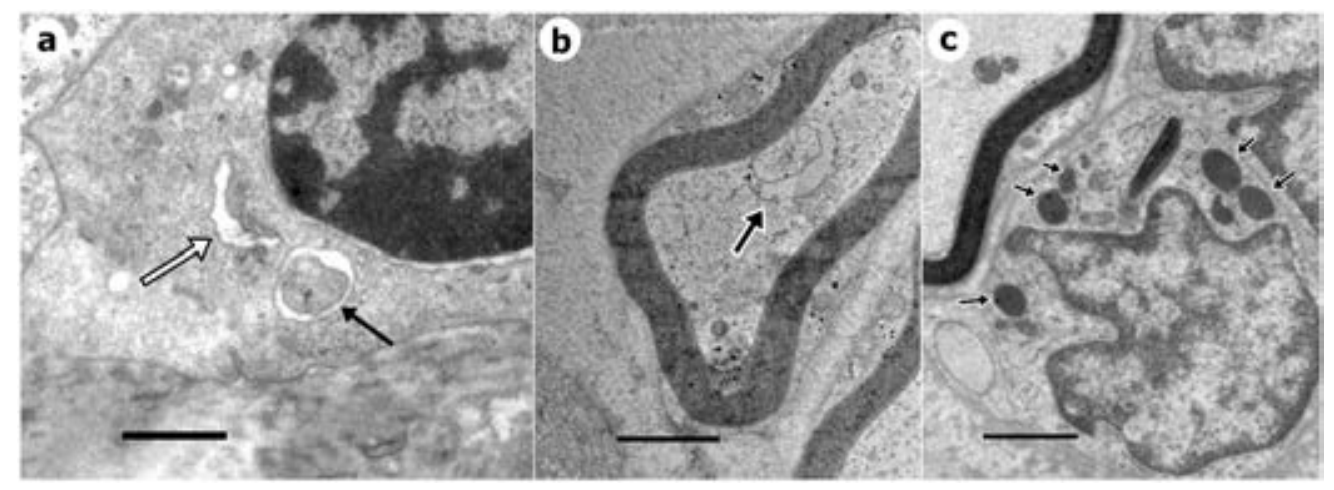

Figure 18. (a) Phagophore (white arrow) and autophagosome (black arrow) in a Schwann cell in a patient with inflammatory neuropathy. (b) Autophagosome in a myelinated axon (arrow) in a patient with CIAP. (c) Lysosomes in a Schwann cell (arrows) in a patient with inflammatory neuropathy. Scale bars $=1 \mu \mathrm{m}$. Human sural nerve (electron micrograph).

Together, these results show that autophagy exists in different pathological conditions, and in different nerves in human. The results also show that autophagy is regulated differently in pathological conditions compared to normal nerves. The method used in this study (EM) is considered the gold standard for monitoring autophagy; it shows the existence of autophagy, and it can be used for the quantification of autophagy structures. As discussed in paper 1, autophagy is a dynamic process, and one of the limitations of EM is that it does not show the autophagic flux. Further investigation using robust autophagy assay, for instance quantification of autophagic proteins and receptors, is needed to understand how autophagy is regulated in peripheral neuropathy, and to understand if activation or inhibition of autophagy affects nerve healing after injury. 


\section{Paper 3}

\section{Background}

Nerve repair and reconstruction after an injury in diabetic patients is a challenging task. Nerve conduits can be used to reconnect the injured nerve with good recovery when the gap between the proximal and distal nerve stumps is short. There are possibilities to also provide neurotrophic factors in such conduits, but there are challenges in using such factors due to the complexity of their effects. Previously, I found that autophagy is regulated differently in PNS of patients with peripheral neuropathy. Here, I hypothesize that activation of autophagy improves axonal regeneration in the sciatic nerve of rats with type 2 diabetes after nerve reconstruction using a conduit.

The aim of this study was to investigate the effect of autophagy activation on axonal regeneration, to construct a biological nerve conduit to guide axonal regeneration, and to make proteome profile of the injured nerve in GK rats. Autophagy was activated with rapamycin in the injured and reconstructed sciatic nerve of GK rats.

I used collagen nerve conduits (CNC) containing either NGF or NGF + rapamycin to reconstruct and reconnect the transected sciatic nerves. Samples from CNC, and proximal and distal stumps of the injured nerve were collected after 1, 4, and 8 weeks of injury.

\section{Results and discussion}

My results showed that the nerve injury in sciatic nerve of GK rats significantly increased LC3 after 1, 4, and 8 weeks of injury at both the proximal and distal stumps when conduits with NGF were used. Regarding p62, the immunoreactivity was significantly increased 1 week after injury in both the proximal and distal stumps, but significantly decreased in the distal stump 4 weeks after injury. The high levels of LC3 suggest that autophagy was activated by nerve injury and reconstruction. On the other hand, the higher levels of p62 mean that autophagic flux was either blocked at week 1 (and therefore the number of autophagosomes was increased), or that the expression of p62 was upregulated to a level more than the autophagy machinery could use (Figure 19a; b).

Rapamycin with NGF also significantly increased LC3 levels 1, 4, and 8 weeks after injury in both the proximal and distal stumps, and significantly decreases p62 levels 1 , and 4 weeks after injury in both proximal and distal stumps. When treated with rapamycin autophagic flux was active from week 1 to week 4 as observed by high LC3 fluorescence intensity and low p62 fluorescence intensity (Figure 19a; b). 


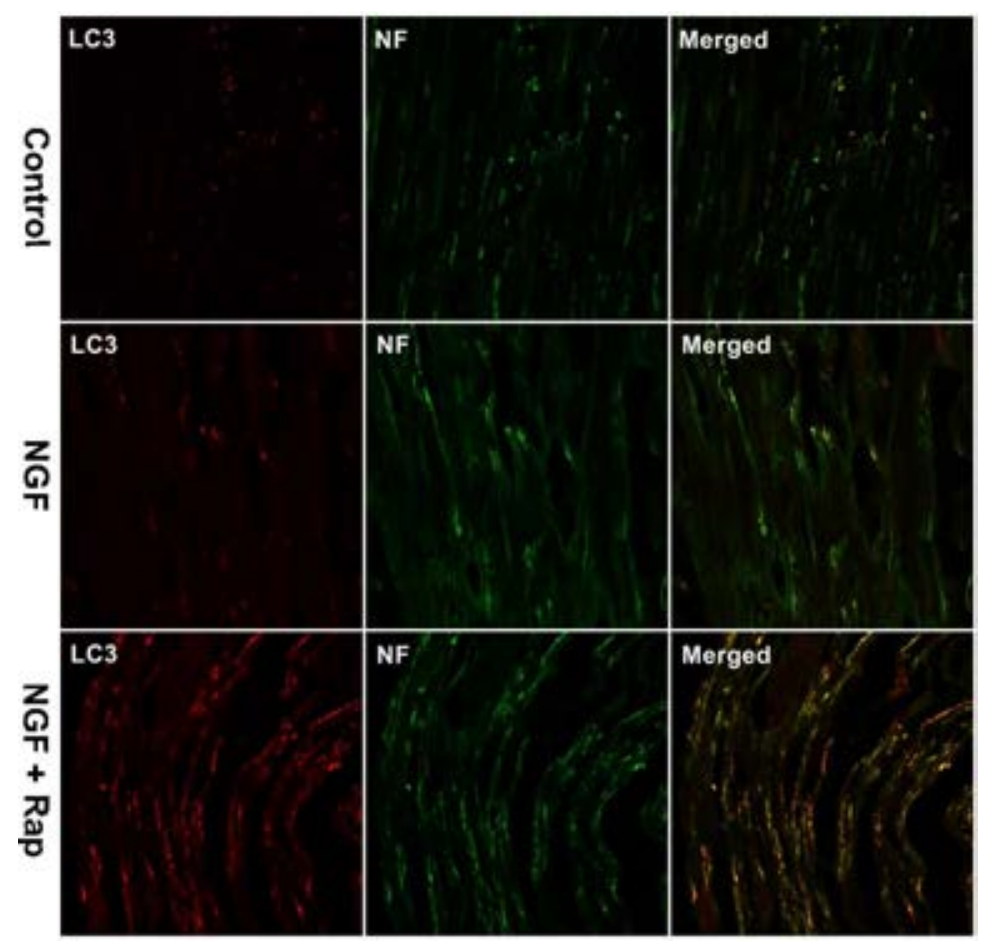

(a)

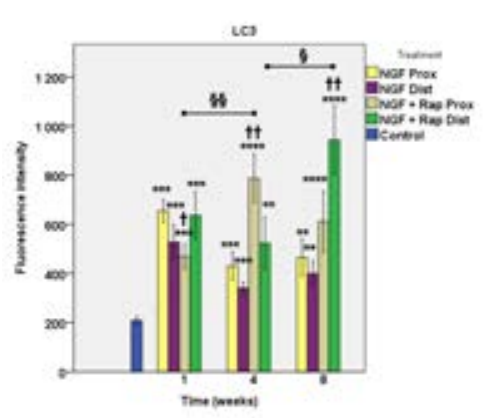

(b)

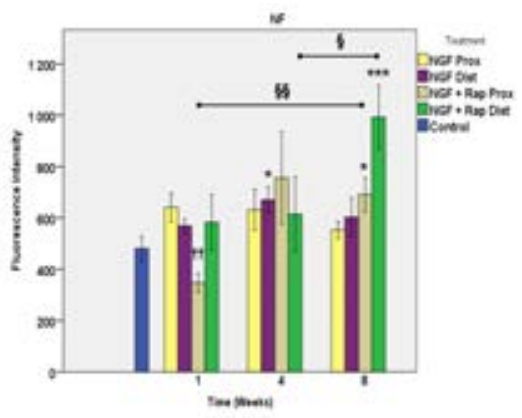

(c)

Figure 19. (a) Immunostaining of the distal stumps of sciatic nerve with antibodies against LC3 and NF 8 weeks after transection and reconstruction using collagen nerve conduits containing NGF or NGF + rapamycin (Rap). Controls were non-injured sciatic nerves from GK rats. (b) Densitometry of fluorescence intensity of anti-LC3 antibodies. (c) Densitometry of fluorescence intensity of anti-NF antibodies. NF (neurofilament). ${ }^{*}<0.05$; $* *<0.01, * * *<0.001$; $* * * *<$ 0.0001 vs control. $\dagger$ vs NGF. $\S$ vs different time points. 
My results also showed that axonal regeneration was improved with administration of NGF 4 weeks after injury compared to non-injured controls, and the axonal outgrowth (measured by NF-fluorescence intensity) was similar to that of the non-injured controls at week 8 after injury and reconstruction. In the presence of rapamycin and NGF, axonal outgrowth, as shown by NF-immunoreactivity, was significantly higher 8 weeks after injury in both distal and proximal stumps compared to non-injured controls. Treatment of the injured nerve with rapamycin delayed the axonal regeneration in the first 4 weeks, but at the later stage (week 8) the axonal outgrowth was higher compared to non-injured nerves (Figure 19a; c). This delay in axonal regeneration could be due to the effect of DMSO that was used as solvent. Studies have shown that DMSO affects the structure and functions of sciatic nerve in rats [96], and induces apoptosis in the mouse brain [97].

My findings support the results of previous studies, which have shown that nerve injury upregulates LC3 [98, 99]. Rapamycin has been shown to protect against neurodegeneration by activating autophagy [100], and improves myelination in PNS [101].

Proteomic study of the injured nerves of diabetic rats 4 weeks after surgery identified 798 proteins, and among these 193 proteins were differentially expressed. I have identified and quantified many proteins involved in axonal growth and regeneration, endocytosis, apoptosis, glucose metabolism, and lysosomal function.

ANOVA test showed that treatment of injured nerves with rapamycin + NGF upregulated many proteins that play roles in peripheral nerve growth and axonal regeneration (Figure 20). For instance, Apolipoproteins (APOD and APOE) were upregulated in both proximal and distal stumps of nerves treated with rapamycin + NGF, as well as in the distal stump of nerve treated only with NGF. These proteins increase axonal regeneration in PNS, and regulate oligodendrocyte differentiation and myelination in CNS, as well as protect neurons from apoptosis [102-104]. Serotransferrin (TF), which increases remyelination [105, 106], was upregulated in both the proximal and distal stumps of nerves treated with rapamycin + NGF.

Results of ANOVA test also showed that myelin-related proteins, i.e. the myelin basic protein (MBP), Myelin protein 0 (MPZ), myelin-associated glycoprotein (MAG), and myelin proteolipid protein (PLP1), were downregulated in nerves treated only with NGF, but in the proximal stump of nerves treated with rapamycin + NGF their expression was normalized. Protein Rab GDP dissociation inhibitor alpha (GDI1), dihydropyrimidinaserelated protein 2 (DPYSL2 - CRMP-2), PLP1, thioredoxin (TXN), MAG, MBP, CD9 antigen (CD9), alpha-synuclein (SNCA), tubulin beta-3 chain (TUBB3), and protein NDRG1 (NDRG1) were found to be downregulated at proximal and distal stumps in the presence of NGF, and in the presence of rapamycin, the expression of these proteins was downregulated at distal stumps of nerves, but were normalized in the proximal stumps. These proteins regulate nervous system development, axonogenesis, glial cell differentiation, myelination, and myelin maintenance [107-115]. 

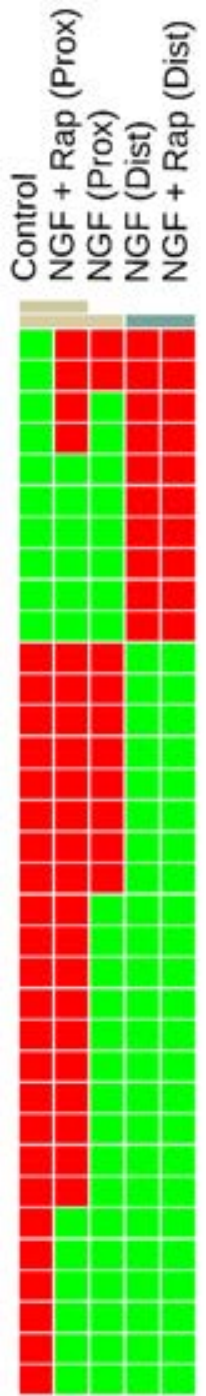

Fibronectin (FN1)

Heterogeneous nuclear ribonucleoproteins A2/B1 (HNRNPA2B1)

Apolipoprotein D (APOD)

Apolipoprotein E (APOE)

Granulins (GRN)

Thrombospondin-4 (THBS4)

Myristoylated alanine-rich C-kinase substrate (MARCKS)

Clusterin (CLU)

Neuromodulin (GAP43)

Heterogeneous nuclear ribonucleoprotein K (HNRNPK)

Glucose-6-phosphate isomerase (GPI)

Neurofilament light polypeptide (NEFL)

$2^{\prime}, 3^{\prime}$-cyclic-nucleotide $3^{\prime}$-phosphodiesterase (CNP)

Peripherin (PRPH)

Periaxin (PRX)

Ubiquitin carboxyl-terminal hydrolase isozyme L1 (UCHL1)

Neurofilament heavy polypeptide (NEFH)

Neurofilament medium polypeptide (NEFM)

Rab GDP dissociation inhibitor alpha (GDI1)

Protein NDRG1 (NDRG1)

Tubulin beta-3 chain (TUBB3)

Dihydropyrimidinase-related protein 2 (DPYSL2)

Alpha-synuclein (SNCA)

Myelin basic protein (MBP)

Myelin-associated glycoprotein (MAG)

Thioredoxin (TXN)

CD9 antigen (CD9)

Myelin proteolipid protein (PLP1)

EH domain-containing protein 1 (EHD1)

Kalirin (KALRN)

Fibromodulin (FMOD)

Protein deglycase DJ-1 (PARK7)

Gelsolin (GSN)

Protein S100-B (S100B)

Upregulated

Downregulated

Figure 20. Heatmap shows proteins involved in nerve development, axonal growth, and myelination in injured sciatic nerves treated with NGF or NGF + rapamycin (Rap) at proximal and distal stumps as well as controls. The distal stumps of NGF and NGF + rapamycin had similar proteome profiles while the effect of rapamycin was obvious in the proximal stump.

Results of ANOVA also showed that many proteins involved in apoptosis (Figure 21) were regulated differentially in the sciatic nerve 4 weeks after injury. Among those proteins MPZ, SNCA, and alpha-crystallin B chain (CRYAB) were downregulated at the proximal and distal stumps of NGF group as well as distal stump of nerves treated with NGF + 
rapamycin. MPZ and $\mathrm{CRYAB}$ have a protective role and they negatively regulate apoptosis in SC, while SNCA negatively regulate apoptosis in neurons [116-118].

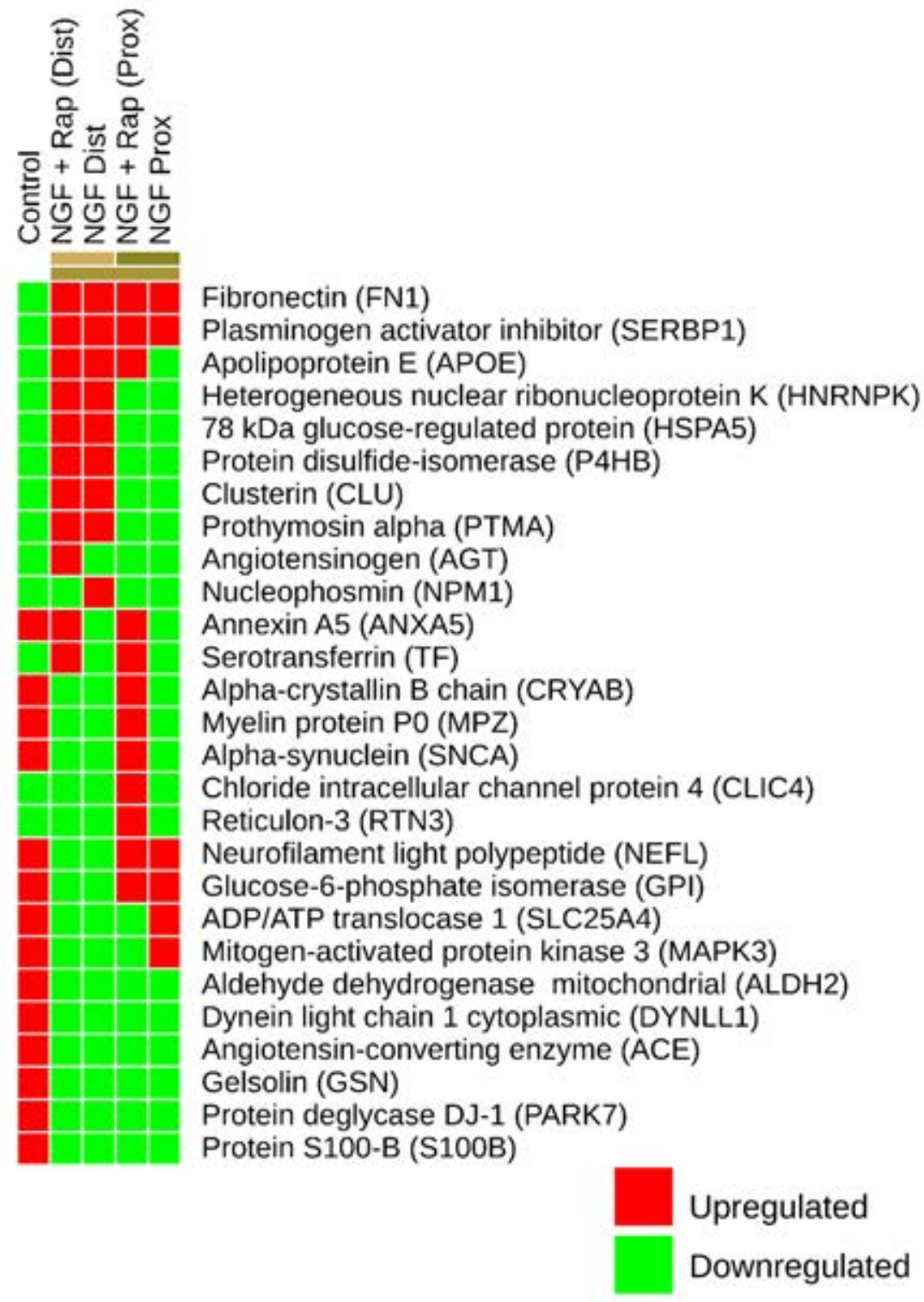

Figure 21. Heatmap shows proteins involved in apoptosis regulation in injured nerves treated with NGF or NGF + rapamycin (Rap) at the proximal and distal stumps as well as controls. Rapamycin in proximal stump of nerve upregulate many proteins negatively regulate glial and neuronal apoptosis. 
Following ANOVA, a t-test was performed to find out which proteins are regulated by rapamycin. We found 69 proteins regulated by nerve injury in the proximal stump and 113 proteins in the distal stump. We also identified 31 proteins in the proximal stump and 9 proteins in the distal stump were regulated by rapamycin (Figure 22). These proteins were mainly downregulated by nerve injury and upregulated to levels similar to the level at noninjured nerves by rapamycin. These proteins involved in response to oxidative stress, regulation of inflammatory response, and cell proliferation.

Together, the results of proteomic analysis show that rapamycin upregulates many proteins involved in axonal regeneration and cell survival.

In conclusion, these findings show that treatment of nerve injury with NGF + rapamycin significantly improves axonal regeneration, and the regenerating axons are stabilized at later stage of injury ( 8 weeks). Rapamycin regulates the expression of many proteins involved in axonal regeneration and cell survival. This study gives insight into the role of autophagy in peripheral nerve degeneration and regeneration at the molecular level. 
a

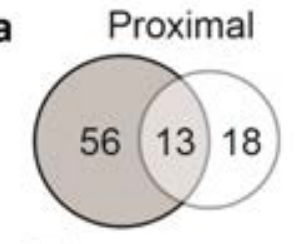

$\square$ Changed by rapamycin Changed by transection

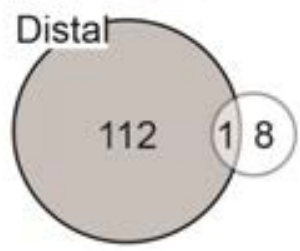

C

\section{Proximal}

Selenium-binding protein 1

PDZ and LIM domain protein 3

PDZ domain-containing protein 2

Hemopexin

Isocitrate dehydrogenase cytoplasmic

Fatty acid-binding protein, adipocyte

L-lactate dehydrogenase $B$ chain

Rho GDP-dissociation inhibitor 1

Glutathione peroxidase 3

Mast cell carboxypeptidase A

Alpha-synuclein

Guanine deaminase b Rapamycin

(log change)

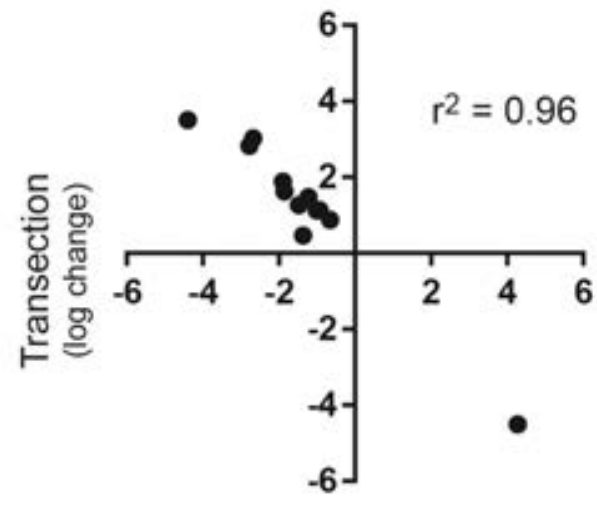

\begin{tabular}{ccccc} 
Transection & \multicolumn{3}{c}{ Rapamycin } \\
\hline$p$ & Fold change & $p$ & Fold change \\
\hline 0.008 & -6.8 & 0.000 & 7.1 \\
\hline 0.001 & 19.3 & 0.002 & -22.7 \\
\hline 0.010 & -2.6 & 0.006 & 1.4 \\
0.002 & -1.6 & 0.006 & 1.8 \\
0.004 & -6.4 & 0.008 & 8.1 \\
0.006 & -3.7 & 0.016 & 3.7 \\
0.019 & -2.3 & 0.022 & 2.8 \\
0.038 & -2.0 & 0.026 & 2.2 \\
0.007 & $-3,6$ & 0.027 & 3.1 \\
0.001 & -21.1 & 0.029 & 11.4 \\
0.035 & -1.9 & 0.031 & 2.2 \\
0.012 & -2.8 & 0.038 & 2.4 \\
\hline
\end{tabular}

\section{Distal}

Glycerol-3-phosphate dehydrogenase

\section{$\begin{array}{llll}0,000 & -12,0 & 0,003 & 6,2\end{array}$}

Figure 22. Effect of nerve injury and rapamycin on proteome of the sciatic nerve of GK rats. (a) Venn diagrams illustrating the overlap of protein expression changes induced by nerve transection (NGF vs non-injured controls) and rapamycin treatment in injured nerves (NGF vs NGF + rapamycin). Proteins were identified by LC-MS/MS. (b) Plot of the magnitude and direction of change in proteins regulated both by nerve transection and rapamycin treatment. Note that the addition of rapamycin in the conduits tend to normalize the changes induced by transection (i.e. they change the protein levels in the opposite direction but with a similar magnitude). (c) List of the proteins that were regulated by transection and rapamycin. 


\section{CONCLUSION}

To my knowledge, this is the first report on the presence of autophagy in human peripheral nervous system. My results show that the density of autophagy structures correlates positively with the severity of neuropathy. In diabetic GK rats, I found that nerve injury increases the autophagy proteins LC3 and p62, and the administration of a neurotrophic factor, like NGF, is important for nerve regeneration in transected and reconstructed nerve of diabetic GK rats with a moderate blood glucose level. More importantly, I also conclude that activation of autophagy by rapamycin improves axonal regeneration. Rapamycin upregulates many proteins involved in axonal regeneration and cell survival.

\section{Future Perspectives}

In the future, I would like to study the effect of autophagy on the functional recovery of the re-innervated organs. I am also interested in developing methods for an optimal guiding of axonal regeneration and nerve repair and reconstruction. 


\section{ACKNOWLEDGEMENTS}

I would like to express my gratitude to everyone who helped me to do the work described in this thesis, in particular, I would like to thank:

Simin Mohseni: my main supervisor, for trusting me and for accepting me into your small group, and for your patience and your endless support during all steps of my PhD study.

David Engblom, Lars Dahlin, and Maria Turkina: my co-supervisors, for the support and scientific discussion during my $\mathrm{PhD}$.

Rayomand Press, and Kristin Samuelsson at Karolinska institute: collaboration with you was a great experience.

Elina Arnemo, Maria Ntzouni, Maarit Jaarola, Mehrdad Rafat, Vesa Loitto, Chhanda Dutta, Carmen, Mireia Coma Bansell, and Lena Stenberg from Lund University: for your help in the lab, and for being kind to me.

I also would like to thank peoples at the animal facility in particular Anna, Anders, Björn, and Monika: for taking care of my rats, and for your invaluable advice.

I would like to thank Fredrik Elinder, Anders Blomqvist, and Annelie Lindström: for the scientific suggestions and organizational support during my $\mathrm{PhD}$ study.

I also would like to thank Anna Weinhofer, Camilla Höglund, and Annelie Munther for administrative support during my study.

I also would like to thank people on floor 11, in particular Gonzalo Manuel Sanchez, Elahe Mirrasekhian, Anna Klawonn, and Michael Fritz. It was great to meet you, and all conversations we had were very interesting and helpful.

Finally, I would like to thank my family in Sudan, my mother and siblings, who support me all the time and give me hope for better future. 


\section{REFERENCES}

1. Topp KS, Boyd BS (2012) Peripheral nerve: from the microscopic functional unit of the axon to the biomechanically loaded macroscopic structure. J Hand Ther 25:142-152.

2. Bilbao JM, Schmidt RE (2015) Normal anatomy of the peripheral (sural) nerve. In: Biopsy Diagnosis Peripher. Neuropathy. Springer, pp 21-41

3. Mizisin AP, Weerasuriya A (2011) Homeostatic regulation of the endoneurial microenvironment during development, aging and in response to trauma, disease and toxic insult. Acta Neuropathol 121:291-312. doi: 10.1007/s00401-010-0783-X

4. Dahlin LB (2004) The biology of nerve injury and repair. J Am Soc Surg Hand 4:143-155. doi: 10.1016/j.jassh.2004.06.006

5. Espinosa-Medina I, Outin E, Picard CA, et al (2014) Parasympathetic ganglia derive from Schwann cell precursors. Science (80- ) 345:87-90.

6. Jessen KR, Mirsky R (2016) The repair Schwann cell and its function in regenerating nerves. J Physiol 594:3521-3531. doi: 10.1113/JP270874

7. Goldberg JL, Barres BA (1998) Neural regeneration: Extending axons from bench to brain. Curr Biol 8:R310-R312. doi: 10.1016/S0960-9822(98)70195-2

8. Goldberg JL (2003) How does an axon grow? Genes Dev 17:941-58. doi: 10.1101/gad.1062303

9. Dučić T, Quintes S, Nave K-A, et al (2011) Structure and composition of myelinated axons: a multimodal synchrotron spectro-microscopy study. J Struct Biol 173:202-212. doi: 10.1016/j.jsb.2010.10.001

10. Bilbao JM, Schmidt RE (2015) Schwann Cells and Myelin in the Peripheral Nervous System. In: Biopsy Diagnosis Peripher. Neuropathy. Springer, pp 85-109

11. Miyamoto Y, Yamauchi J (2014) Recent insights into molecular mechanisms that control growth factor receptor-mediated Schwann cell morphological changes during development. In: Schwann Cell Dev. Pathol. Springer, pp 5-27

12. Scherer SS, Arroyo EJ (2002) Recent progress on the molecular organization of myelinated axons. J Peripher Nerv Syst 7:1-12.

13. Savastano LE, Laurito SR, Fitt MR, et al (2014) Sciatic nerve injury: a simple and subtle model for investigating many aspects of nervous system damage and recovery. J Neurosci Methods 227:166-180. doi: 10.1016/j.jneumeth.2014.01.020

14. Waller A (1850) Experiments on the section of the glossopharyngeal and hypoglossal nerves of the frog, and observations of the alterations produced thereby in the structure of their primitive fibres. Philos Trans R Soc London 140:423-429.

15. Thumm M, Simons M (2015) Myelinophagy: Schwann cells dine in. J Cell Biol 210:9-10. doi: 10.1083/jcb.201506039

16. Chan KM, Gordon T, Zochodne DW, Power HA (2014) Improving peripheral nerve regeneration: from molecular mechanisms to potential therapeutic targets. Exp Neurol 261:826-835. doi: 10.1016/j.expneurol.2014.09.006

17. Ribeiro-Resende VT, Koenig B, Nichterwitz S, et al (2009) Strategies for inducing the formation of bands of Bungner in peripheral nerve regeneration. Biomaterials 30:5251-5259. doi: 10.1016/j.biomaterials.2009.07.007

18. Gaudet AD, Popovich PG, Ramer MS (2011) Wallerian degeneration: gaining perspective on inflammatory events after peripheral nerve injury. J Neuroinflammation 8:110. doi: 10.1186/1742-2094-8-110

19. Bilbao JM, Schmidt RE (2015) The Axon: Normal Structure and Pathological Alterations. In: Biopsy Diagnosis Peripher. Neuropathy. Springer International Publishing, Cham, pp 51- 
84

20. Allodi I, Udina E, Navarro X (2012) Specificity of peripheral nerve regeneration: Interactions at the axon level. Prog Neurobiol 98:16-37. doi:

10.1016/j.pneurobio.2012.05.005

21. Boyd JG, Gordon T (2003) Neurotrophic factors and their receptors in axonal regeneration and functional recovery after peripheral nerve injury. Mol Neurobiol 27:277-324. doi: 10.1385/MN:27:3:277

22. Meiri KF, Pfenninger KH, Willard MB (1986) Growth-associated protein, GAP-43, a polypeptide that is induced when neurons extend axons, is a component of growth cones and corresponds to pp46, a major polypeptide of a subcellular fraction enriched in growth cones. Proc Natl Acad Sci 83:3537-3541.

23. Ray WZ, Mackinnon SE (2010) Management of nerve gaps: autografts, allografts, nerve transfers, and end-to-side neurorrhaphy. Exp Neurol 223:77-85. doi: 10.1016/j.expneurol.2009.03.031

24. Daly W (2014) A biomaterials approach to peripheral nerve repair. National University of Ireland

25. Merrell GA, Barrie KA, Katz DL, Wolfe SW (2001) Results of nerve transfer techniques for restoration of shoulder and elbow function in the context of a meta-analysis of the English literature. J Hand Surg Am 26:303-314.

26. Leechavengvongs S, Witoonchart K, Uerpairojkit C, Thuvasethakul P (2003) Nerve transfer to deltoid muscle using the nerve to the long head of the triceps, part II: a report of 7 cases. $\mathrm{J}$ Hand Surg Am 28:633-638.

27. Bontioti E, Kanje M, Lundborg G, Dahlin LB (2005) End- to- side nerve repair in the upper extremity of rat. J Peripher Nerv Syst 10:58-68.

28. Isaacs J, Browne T (2014) Overcoming short gaps in peripheral nerve repair: conduits and human acellular nerve allograft. Hand 9:131-137.

29. Bril V (2005) Diabetic Peripheral Neuropathy: Advances In Understanding And Treatment. Proceedings 5:264-269.

30. Shaw JE, Sicree RA, Zimmet PZ (2010) Global estimates of the prevalence of diabetes for 2010 and 2030. Diabetes Res Clin Pract 87:4-14. doi: 10.1016/j.diabres.2009.10.007

31. Malik RA, Tesfaye S, Newrick PG, et al (2005) Sural nerve pathology in diabetic patients with minimal but progressive neuropathy. Diabetologia 48:578-85. doi: 10.1007/s00125004-1663-5

32. Edwards JL, Vincent AM, Cheng HT, Feldman EL (2008) Diabetic neuropathy: mechanisms to management. Pharmacol Ther 120:1-34. doi: 10.1016/j.pharmthera.2008.05.005

33. Bilbao JM, Schmidt RE (2015) Neuropathy Associated with Endocrine and Metabolic Disease. In: Biopsy Diagnosis Peripher. Neuropathy. Springer, pp 331-354

34. Thomsen NOB, Cederlund RI, Andersson GS, et al (2014) Carpal tunnel release in patients with diabetes: a 5-year follow-up with matched controls. J Hand Surg Am 39:713-720. doi: 10.1016/j.jhsa.2014.01.012

35. Obrosova IG (2009) Diabetes and the peripheral nerve. Biochim Biophys Acta (BBA)Molecular Basis Dis 1792:931-940. doi: 10.1016/j.bbadis.2008.11.005

36. Vinik AI, Maser RE, Mitchell BD, Freeman R (2003) Diabetic autonomic neuropathy. Diabetes Care 26:1553-1579.

37. Tracy JA, Engelstad JK, Dyck PJB (2009) Microvasculitis in diabetic lumbosacral radiculoplexus neuropathy. J Clin Neuromuscul Dis 11:44. doi:

10.1097/CND.0b013e3181b1eb6d.Microvasculitis

38. Thaisetthawatkul P, Dyck PJB (2010) Treatment of Diabetic and Nondiabetic Lumbosacral Radiculoplexus Neuropathy. Curr Treat Options Neurol 12:95-99. doi: 10.1007/s11940-0100059-8

39. Bilbao JM, Schmidt RE (2015) The Peripheral Nerve Vasculature. In: Biopsy Diagnosis Peripher. Neuropathy. Springer, pp 111-122 
40. Feldman EL, Nave KA, Jensen TS, Bennett DLH (2017) New Horizons in Diabetic Neuropathy: Mechanisms, Bioenergetics, and Pain. Neuron 93:1296-1313. doi: 10.1016/j.neuron.2017.02.005

41. Yagihashi S, Mizukami H, Sugimoto K (2011) Mechanism of diabetic neuropathy: where are we now and where to go? J Diabetes Investig 2:18-32. doi: 10.1111/j.20401124.2010.00070.x

42. Malik RA, Tesfaye S, Thompson SD, et al (1993) Endoneurial localisation of microvascular damage in human diabetic neuropathy. Diabetologia 36:454-459.

43. Malik RA, Newrick PG, Sharma AK, et al (1989) Microangiopathy in human diabetic neuropathy: relationship between capillary abnormalities and the severity of neuropathy. Diabetologia 32:92-102.

44. Low PA, Nickander KK, Tritschler HJ (1997) The roles of oxidative stress and antioxidant treatment in experimental diabetic neuropathy. Diabetes 46:S38-S42.

45. O’Brien PD, Hinder LM, Sakowski SA, Feldman EL (2014) ER stress in diabetic peripheral neuropathy: a new therapeutic target. Antioxid Redox Signal 21:621-633. doi: 10.1089/ars.2013.5807

46. Singer MA, Vernino SA, Wolfe GI (2012) Idiopathic neuropathy: new paradigms, new promise. J Peripher Nerv Syst 17:43-49. doi: 10.1111/j.1529-8027.2012.00395.x

47. Visser NA, Vrancken AFJE, Van Der Schouw YT, et al (2013) Chronic idiopathic axonal polyneuropathy is associated with the metabolic syndrome. Diabetes Care 36:817-822. doi: 10.2337/dc12-0469

48. Visser NA, Notermans NC, Degen LAR, et al (2014) Chronic idiopathic axonal polyneuropathy and vitamin B6: a controlled population- based study. J Peripher Nerv Syst 19:136-144. doi: 10.1111/jns5.12063

49. Novella SP, Inzucchi SE, Goldstein JM (2001) The frequency of undiagnosed diabetes and impaired glucose tolerance in patients with idiopathic sensory neuropathy. Muscle Nerve 24:1229-1231.

50. Teunissen LL, Franssen H, Wokke JHJ, et al (2002) Is cardiovascular disease a risk factor in the development of axonal polyneuropathy? J Neurol Neurosurg Psychiatry 72:590-595.

51. Hughes RAC, Umapathi T, Gray IA, et al (2004) A controlled investigation of the cause of chronic idiopathic axonal polyneuropathy. Brain 127:1723-1730. doi: 10.1093/brain/awh192

52. Erdmann PG, van Genderen FR, Teunissen LL, et al (2010) Pain in patients with chronic idiopathic axonal polyneuropathy. Eur Neurol 64:58-64. doi: 10.1159/000315037

53. Robert F, Edan G, Nicolas G, et al (2015) A retrospective study on the efficacy and safety of intraveinous immunoglobulin (Tegeline ${ }^{\circledR}$ ) in patients with chronic inflammatory demyelinating polyneuropathy. Presse Med 44:e291-e300. doi: 10.1016/j.lpm.2014.10.021

54. Köller H, Kieseier BC, Jander S, Hartung H-P (2005) Chronic inflammatory demyelinating polyneuropathy. N Engl J Med 352:1343-1356. doi: 10.1056/NEJMra041347

55. Kerasnoudis A (2013) Nerve ultrasound in a case of chronic inflammatory demyelinating neuropathy. Muscle and Nerve 47:443-446. doi: 10.1002/mus.23624

56. Bilbao JM, Schmidt RE (2015) The Inflammatory Demyelinating Neuropathies. In: Biopsy Diagnosis Peripher. Neuropathy. Springer, pp 161-196

57. Rajabally YA (2013) Subcutaneous immunoglobulin therapy for inflammatory neuropathy: current evidence base and future prospects. J Neurol Neurosurg Psychiatry 85:jnnp-2013. doi: 10.1136/jnnp-2013-305644

58. Gwathmey KG, Burns TM, Collins MP, Dyck PJB (2014) Vasculitic neuropathies. Lancet Neurol 13:67-82. doi: 10.1016/S1474-4422(13)70236-9

59. Collins MP, Periquet MI (2008) Isolated vasculitis of the peripheral nervous system. Clin Exp Rheumatol 26:S118. doi: 2373 [pii]

60. Blaes F (2015) Diagnosis and therapeutic options for peripheral vasculitic neuropathy. Ther Adv Musculoskelet Dis 7:45-55. doi: 10.1177/1759720x14566617

61. Levine B, Kroemer G (2008) Autophagy in the pathogenesis of disease. Cell 132:27-42. doi: 
10.1016/j.cell.2007.12.018

62. Lilienbaum A (2013) Relationship between the proteasomal system and autophagy. Int J Biochem Mol Biol 4:1-26.

63. Mizushima N, Yoshimori T, Levine B (2010) Methods in mammalian autophagy research. Cell 140:313-326. doi: 10.1016/j.cell.2010.01.028

64. Sridhar S, Botbol Y, Macian F, Cuervo AM (2012) Autophagy and disease: always two sides to a problem. J Pathol 226:255-273. doi: 10.1002/path.3025

65. Feng Y, He D, Yao Z, Klionsky DJ (2014) The machinery of macroautophagy. Cell Res 24:24-41. doi: 10.1038/cr.2013.168

66. Vernon PJ, Tang D (2013) Eat-me: autophagy, phagocytosis, and reactive oxygen species signaling. Antioxid Redox Signal 18:677-691. doi: 10.1089/ars.2012.4810

67. Tooze SA, Abada A, Elazar Z (2014) Endocytosis and autophagy: exploitation or cooperation? Cold Spring Harb Perspect Biol 6:a018358. doi: 10.1101/cshperspect.a018358

68. Suzuki K, Ohsumi Y (2007) Molecular machinery of autophagosome formation in yeast, Saccharomyces cerevisiae. FEBS Lett 581:2156-2161. doi: 10.1016/j.febslet.2007.01.096

69. Palmieri M, Impey S, Kang H, et al (2011) Characterization of the CLEAR network reveals an integrated control of cellular clearance pathways. Hum Mol Genet 20:3852-3866. doi: 10.1093/hmg/ddr306

70. Zhou J, Tan S-H, Nicolas V, et al (2013) Activation of lysosomal function in the course of autophagy via mTORC1 suppression and autophagosome-lysosome fusion. Cell Res 23:508523. doi: 10.1038/cr.2013.11

71. Johansen T, Lamark T (2011) Selective autophagy mediated by autophagic adapter proteins. Autophagy 7:279-296. doi: 10.4161/auto.7.3.14487

72. Lippai M, Low P (2014) The role of the selective adaptor p62 and ubiquitin-like proteins in autophagy. Biomed Res Int 2014:832704. doi: 10.1155/2014/832704

73. Kim BW, Kwon DH, Song HK (2016) Structure biology of selective autophagy receptors. BMB Rep 49:73-80. doi: 10.5483/BMBRep.2016.49.2.265

74. Youle RJ, Narendra DP (2011) Mechanisms of mitophagy. Nat Rev Mol Cell Biol 12:9-14.

75. Zientara-Rytter K, Subramani S (2016) Autophagic degradation of peroxisomes in mammals. Biochem Soc Trans 44:431-440. doi: 10.1042/BST20150268

76. Knodler LA, Celli J (2011) Eating the strangers within: host control of intracellular bacteria via xenophagy. Cell Microbiol 13:1319-1327. doi: 10.1111/j.1462-5822.2011.01632.x

77. Gomez-Sanchez JA, Carty L, Iruarrizaga-Lejarreta M, et al (2015) Schwann cell autophagy, myelinophagy, initiates myelin clearance from injured nerves. J Cell Biol 210:153-168. doi: 10.1083/jcb.201503019

78. Jiang P, Mizushima N (2014) Autophagy and human diseases. Cell Res 24:69-79. doi: 10.1038/cr.2013.161

79. Boland B, Kumar A, Lee S, et al (2008) Autophagy induction and autophagosome clearance in neurons: relationship to autophagic pathology in Alzheimer's disease. J Neurosci 28:6926-6937. doi: 10.1523/JNEUROSCI.0800-08.2008

80. Nixon RA (2006) Autophagy in neurodegenerative disease: friend, foe or turncoat? Trends Neurosci 29:528-535. doi: 10.1016/j.tins.2006.07.003

81. Yu WH, Cuervo AM, Kumar A, et al (2005) Macroautophagy-a novel $\beta$-amyloid peptidegenerating pathway activated in Alzheimer's disease. J Cell Biol 171:87-98.

82. Cuervo AM, Stefanis L, Fredenburg R, et al (2004) Impaired degradation of mutant $\alpha$ synuclein by chaperone-mediated autophagy. Science (80- ) 305:1292-1295.

83. Ravikumar B, Vacher C, Berger Z, et al (2004) Inhibition of mTOR induces autophagy and reduces toxicity of polyglutamine expansions in fly and mouse models of Huntington disease. Nat Genet 36:585-595.

84. Piao ZX, Wang WS, Xu XJ, et al (2004) Autophagy of neuron axon during regeneration of rat sciatic nerves. J First Mil Med Uni 24:361-364.

85. Mohseni S (2011) Autophagy in insulin-induced hypoglycaemic neuropathy. Pathology 
43:254-260. doi: 10.1097/PAT.0b013e328343c992

86. Bromberg MB (2013) An electrodiagnostic approach to the evaluation of peripheral neuropathies. Phys Med Rehabil Clin 24:153-168.

87. Caress JB, Esper GJ, Rutkove SB (2007) Neurophysiology of Nerve Conduction Studies. In: Clin. Neurophysiol. Prim. Springer, pp 207-216

88. Mallik A, Weir AI (2005) Nerve conduction studies: essentials and pitfalls in practice. J Neurol Neurosurg Psychiatry 76:ii23-ii31.

89. Bilbao JM, Schmidt RE (2015) Clinical Aspects of Peripheral Neuropathy. In: Biopsy Diagnosis Peripher. Neuropathy. Springer, pp 151-159

90. Klionsky DJ, Abdalla FC, Abeliovich H, et al (2016) Guidelines for the use and interpretation of assays for monitoring autophagy. Autophagy 8:445-544. doi: 10.4161/auto.19496

91. Akash MSH, Rehman K, Chen S (2013) Goto-kakizaki rats: Its suitability as non-obese diabetic animal model for spontaneous type 2 diabetes mellitus. Curr Diabetes Rev 9:387396. doi: $10.2174 / 15733998113099990069$

92. Lovric J (2011) Introducing proteomics: from concepts to sample separation, mass spectrometry and data analysis. John Wiley \& Sons

93. Hara T, Nakamura K, Matsui M, et al (2006) Suppression of basal autophagy in neural cells causes neurodegenerative disease in mice. Nature 441:885-889. doi: 10.1038/nature04724

94. Nixon RA, Wegiel J, Kumar A, et al (2005) Extensive involvement of autophagy in Alzheimer disease: an immuno-electron microscopy study. J Neuropathol Exp Neurol 64:113-122.

95. Alves S, Cormier-Dequaire F, Marinello M, et al (2014) The autophagy/lysosome pathway is impaired in SCA7 patients and SCA7 knock-in mice. Acta Neuropathol 128:705-722.

96. Cavaletti G, Oggioni N, Sala F, et al (2000) Effect on the peripheral nervous system of systemically administered dimethylsulfoxide in the rat: a neurophysiological and pathological study. Toxicol Lett 118:103-107. doi: 10.1016/S0378-4274(00)00269-1

97. Hanslick JL, Lau K, Noguchi KK, et al (2009) Dimethyl sulfoxide (DMSO) produces widespread apoptosis in the developing central nervous system. Neurobiol Dis 34:1-10. doi: 10.1016/j.nbd.2008.11.006.Dimethyl

98. Guo J-S, Jing P-B, Wang J-A, et al (2015) Increased autophagic activity in dorsal root ganglion attenuates neuropathic pain following peripheral nerve injury. Neurosci Lett 599:158-163. doi: 10.1016/j.neulet.2015.05.046

99. Sekiguchi A, Kanno H, Ozawa H, et al (2012) Rapamycin promotes autophagy and reduces neural tissue damage and locomotor impairment after spinal cord injury in mice. $\mathrm{J}$ Neurotrauma 29:946-956. doi: 10.1089/neu.2011.1919

100. Pan T, Kondo S, Zhu W, et al (2008) Neuroprotection of rapamycin in lactacystin-induced neurodegeneration via autophagy enhancement. Neurobiol Dis 32:16-25. doi: 10.1016/j.nbd.2008.06.003

101. Nicks J, Lee S, Harris A, et al (2014) Rapamycin improves peripheral nerve myelination while it fails to benefit neuromuscular performance in neuropathic mice. Neurobiol Dis 70:224-236. doi: 10.1016/j.nbd.2014.06.023

102. Nelissen K, Mulder M, Smets I, et al (2012) Liver X receptors regulate cholesterol homeostasis in oligodendrocytes. J Neurosci Res 90:60-71. doi: 10.1002/jnr.22743

103. Hayashi H, Campenot RB, Vance DE, Vance JE (2007) Apolipoprotein E-containing lipoproteins protect neurons from apoptosis via a signaling pathway involving low-density lipoprotein receptor-related protein-1. J Neurosci 27:1933-1941. doi: 10.1523/JNEUROSCI.5471-06.2007

104. Boyles JK, Notterpek LM, Anderson LJ (1990) Accumulation of apolipoproteins in the regenerating and remyelinating mammalian peripheral nerve. Identification of apolipoprotein D, apolipoprotein A-IV, apolipoprotein E, and apolipoprotein A-I. J Biol Chem 265:1780517815. doi: 10.1159/000053308 
105. Adamo AM, Paez PM, Escobar Cabrera OE, et al (2006) Remyelination after cuprizoneinduced demyelination in the rat is stimulated by apotransferrin. Exp Neurol 198:519-529. doi: 10.1016/j.expneurol.2005.12.027

106. Aparicio E, Mathieu P, Pereira Luppi M, et al (2013) The Notch signaling pathway: its role in focal CNS demyelination and apotransferrin-induced remyelination. J Neurochem 127:819-836. doi: 10.1111/jnc.12440

107. Gudz TI, Schneider TE, Haas TA, Macklin WB (2002) Myelin proteolipid protein forms a complex with integrins and may participate in integrin receptor signaling in oligodendrocytes. J Neurosci 22:7398-7407.

108. Hama I, Nakagomi S, Konishi H, Kiyama H (2010) Simultaneous expression of glutathione, thioredoxin-1, and their reductases in nerve transected hypoglossal motor neurons of rat. Brain Res 1306:1-7. doi: 10.1016/j.brainres.2009.10.014

109. Hasegawa Y, Fujitani M, Hata K, et al (2004) Promotion of axon regeneration by myelinassociated glycoprotein and Nogo through divergent signals downstream of Gi/G. J Neurosci 24:6826-6832. doi: 10.1523/JNEUROSCI.1856-04.2004

110. Moskowitz PF, Smith R, Pickett J, et al (1993) Expression of the class III beta-tubulin gene during axonal regeneration of rat dorsal root ganglion neurons. J Neurosci Res 34:129-134. doi: 10.1002/jnr.490340113

111. Patrakitkomjorn S, Kobayashi D, Morikawa T, et al (2008) Neurofibromatosis type 1 (NF1) tumor suppressor, neurofibromin, regulates the neuronal differentiation of PC12 cells via its associating protein, CRMP-2. J Biol Chem 283:9399-9413. doi: 10.1074/jbc.M708206200

112. Phokeo V, Kwiecien JM, Ball AK (2002) Characterization of the optic nerve and retinal ganglion cell layer in the dysmyelinated adult Long Evans Shaker rat: evidence for axonal sprouting. J Comp Neurol 451:213-224. doi: 10.1002/cne.10330

113. Skibinski G, Nakamura K, Cookson MR, Finkbeiner S (2014) Mutant LRRK2 toxicity in neurons depends on LRRK2 levels and synuclein but not kinase activity or inclusion bodies. J Neurosci 34:418-433. doi: 10.1523/JNEUROSCI.2712-13.2014

114. Sundar R, Jeyasekharan AD, Pang B, et al (2016) Low levels of NDRG1 in nerve tissue are predictive of severe paclitaxel-induced neuropathy. PLoS One 11:e0164319. doi: 10.1371/journal.pone.0164319

115. Terada N, Baracskay K, Kinter M, et al (2002) The tetraspanin protein, CD9, is expressed by progenitor cells committed to oligodendrogenesis and is linked to beta1 integrin, CD81, and Tspan-2. Glia 40:350-359. doi: 10.1002/glia.10134

116. Lei L, Han D, Gong S, et al (2010) Mpz gene suppression by shRNA increases Schwann cell apoptosis in vitro. Neurol Sci Off J Ital Neurol Soc Ital Soc Clin Neurophysiol 31:603-608. doi: 10.1007/s10072-010-0341-2

117. Monti B, Polazzi E, Batti L, et al (2007) Alpha-synuclein protects cerebellar granule neurons against 6-hydroxydopamine-induced death. J Neurochem 103:518-530. doi: 10.1111/j.14714159.2007.04778.x

118. Ousman SS, Tomooka BH, van Noort JM, et al (2007) Protective and therapeutic role for alphaB-crystallin in autoimmune demyelination. Nature 448:474-479. doi: 10.1038/nature05935 


\section{Papers}

The papers associated with this thesis have been removed for copyright reasons. For more details about these see:

http://urn.kb.se/resolve?urn=urn:nbn:se:liu:diva-142125 